Babiloni C, Del Percio C, Lizio R, Noce G, Lopez S, Soricelli A, Ferri R, Nobili F, Arnaldi D, Fama F, Aarsland D, Orzi F, Buttinelli C, Giubilei F, Onofrj M, Stocchi F, Stirpe P, Fuhr P, Gschwandtner U, Ransmayr G, Garn H, Fraioli L, Pievani M, Frisoni GB, D'Antonio F, De Lena C, Guntekin B, Hanoglu L, Basar E, Yener G, Emek-Savas DD, Triggiani Al, Franciotti R, Taylor JP, Vacca L, De Pandis MF, Bonanni L.

Abnormalities of resting-state functional cortical connectivity in patients with dementia due to Alzheimer's and Lewy body diseases: an EEG study. Neurobiology of Aging 2018, 65, 18-40

\section{Copyright:}

(C) 2018. This manuscript version is made available under the CC-BY-NC-ND 4.0 license

DOI link to article:

https://doi.org/10.1016/j.neurobiolaging.2017.12.023

Date deposited:

$07 / 03 / 2018$

Embargo release date:

30 December 2018

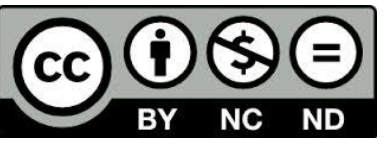

This work is licensed under a

Creative Commons Attribution-NonCommercial-NoDerivatives 4.0 International licence 


\title{
ABNORMALITIES OF RESTING STATE FUNCTIONAL CORTICAL CONNECTIVITY IN PATIENTS WITH DEMENTIA DUE TO ALZHEIMER'S AND LEWY BODY DISEASES: AN EEG STUDY
}

\author{
Claudio Babiloni ${ }^{1,2}$, Claudio Del Percio ${ }^{3}$, Roberta Lizio ${ }^{1,2}$, Giuseppe Noce ${ }^{3}$, Susanna Lopez ${ }^{1}$, Andrea Soricelli ${ }^{3,4}$, \\ Raffaele Ferri ${ }^{5}$, Flavio Nobili ${ }^{6}$, Dario Arnaldi ${ }^{6}$, Francesco Famà ${ }^{6}$, Dag Aarsland ${ }^{7}$, Francesco Orzi ${ }^{8}$, Carla \\ Buttinelli ${ }^{8}$, Franco Giubilei ${ }^{8}$, Marco Onofr ${ }^{9}$, Fabrizio Stocchi ${ }^{2}$, Paola Stirpe ${ }^{2}$, Peter Fuhr ${ }^{10}$, Ute \\ Gschwandtner ${ }^{10}$, Gerhard Ransmayr ${ }^{11}$, Heinrich Garn ${ }^{12}$, Fabiola Sorpresi ${ }^{13}$, Michela Pievani ${ }^{14}$, Giovanni B. \\ Frisoni ${ }^{14,15}$, Fabrizia D'Antonio ${ }^{16}$, Carlo De Lena ${ }^{16}$, Bahar Güntekin ${ }^{17}$, Lutfu Hanoğlu ${ }^{18}$, Erol Başar ${ }^{19}$, Görsev \\ Yener $^{19}$, Derya Durusu Emek-Savaş ${ }^{20}$, Antonio Ivano Triggiani ${ }^{21}$, Raffaella Franciotti ${ }^{9}$, John Paul Taylor ${ }^{22}$, \\ Maria Francesca De Pandis ${ }^{13}$, and Laura Bonanni ${ }^{9}$
${ }^{1}$ Department of Physiology and Pharmacology "Vittorio Erspamer", University of Rome "La Sapienza", Rome, Italy; 2 Institute for Research and Medical Care, IRCCS San Raffaele Pisana, Rome, Italy; ${ }^{3}$ Department of Integrated Imaging, IRCCS SDN, Naples, Italy;
${ }^{4}$ Department of Motor Sciences and Healthiness, University of Naples Parthenope, Naples, Italy; \\ ${ }^{5}$ Department of Neurology, IRCCS Oasi Institute for Research on Mental Retardation and Brain Aging, Troina, Enna, Italy; \\ ${ }^{6}$ Clinical Neurology, dept of Neuroscience (DiNOGMI), University of Genoa and IRCCS AOU S Martino-IST, Genoa, Italy; \\ 7 Department of Old Age Psychiatry, King's College University, London, United Kingdom; \\ ${ }^{8}$ Department of Neuroscience, Mental Health and Sensory Organs, University of Rome "La Sapienza", Rome, Italy; \\ ${ }^{9}$ Department of Neuroscience Imaging and Clinical Sciences and CESI, University G d'Annunzio of Chieti-Pescara, Chieti, \\ Italy; \\ 10 Universitätsspital Basel, Abteilung Neurophysiologie, Petersgraben 4, 4031 Basel, Switzerland; \\ ${ }^{11}$ Department of Neurology and Psychiatry and Faculty of Medicine, Johannes Kepler University Linz, General Hospital of \\ the City of Linz, A-4020 Linz, Krankenhausstr. 9, Austria; \\ ${ }^{12}$ AlT Austrian Institute of Technology GmbH, Vienna, Austria; \\ ${ }^{13}$ Hospital San Raffaele of Cassino, Italy; \\ ${ }^{14}$ Laboratory of Alzheimer's Neuroimaging and Epidemiology, IRCCS Istituto Centro San Giovanni di Dio Fatebenefratelli, \\ Brescia, Italy; \\ ${ }^{15}$ Memory Clinic and LANVIE - Laboratory of Neuroimaging of Aging, University Hospitals and University of Geneva, \\ Geneva, Switzerland; \\ ${ }^{16}$ Department of Neurology and Psychiatry, Sapienza, University of Rome, Italy; \\ ${ }^{17}$ Department of Biophysics, Istanbul Medipol University, Istanbul, Turkey; \\ ${ }^{18}$ Department of Neurology, University of Istanbul-Medipol, Istanbul, Turkey; \\ ${ }_{19}$ IBG, Departments of Neurology and Neurosciences, Dokuz Eylül University, Izmir, Turkey; \\ ${ }^{20}$ Department of Psychology and Department of Neurosciences, Dokuz Eylül University, Izmir, Turkey; \\ ${ }^{21}$ Department of Clinical and Experimental Medicine, University of Foggia, Foggia, Italy; \\ 22 Institute of Neuroscience, Newcastle University, Newcastle, UK.
}

Corresponding author: Prof. Claudio Babiloni, Ph.D.

Department of Physiology and Pharmacology "V. Erspamer"

University of Rome "La Sapienza"

P. le A. Moro 5, 00185, Rome, Italy

Phone: +390649910989

E-mail: claudio.babiloni@uniroma1.it

Running title: Functional brain connectivity in Dementia.

Keywords: Functional brain connectivity; Resting state EEG rhythms; Neurodegenerative diseases; Dementia; Alzheimer's disease; Parkinson's disease; Dementia with Lewy Bodies.

\section{Acknowledgements}

The present study was developed based on the data of the informal European Consortia PDWAVES and E-DLB. The members and institutional affiliations of the Consortium are reported in the cover page of this manuscript. 


\section{Abstract}

Previous evidence showed abnormal posterior sources of resting state delta $(<4 \mathrm{~Hz})$ and alpha $(8-12 \mathrm{~Hz})$ rhythms in patients with Alzheimer's disease with dementia (ADD), Parkinson's disease with dementia (PDD), and Lewy body dementia (DLB), as cortical neural synchronization markers in quiet wakefulness. Here we tested the hypothesis of additional abnormalities in functional cortical connectivity computed in those sources, in ADD, considered as a "disconnection cortical syndrome", in comparison with PDD and DLB.

Resting state eyes-closed electroencephalographic (rSEEG) rhythms had been collected in 42 ADD, 42 PDD, 34 DLB, and 40 normal healthy elderly (Nold) subjects. eLORETA freeware estimated the functional lagged linear connectivity (LLC) from rsEEG cortical sources in delta, theta, alpha, beta, and gamma bands. Area under Receiver operating characteristic (AUROC) curve indexed the classification accuracy between Nold and diseased individuals (only values $>0.7$ were considered).

Interhemispheric and intrahemispheric LLCs in widespread delta sources were abnormally higher in ADD group and, unexpectedly, normal in DLB and PDD groups. Intrahemispheric LLC was reduced in widespread alpha sources dramatically in ADD, markedly in DLB, and moderately in PDD group. Furthermore, the interhemispheric LLC in widespread alpha sources showed lower values in ADD and DLB than PDD. At the individual level, AUROC curves of LLC in alpha sources exhibited better classification accuracies for the discrimination of ADD vs. Normal elderly (Nold) individuals (0.84) than for DLB vs. Nold (0.78) and PDD vs. Nold (0.75).

Functional cortical connectivity" markers in delta and alpha sources suggest a more compromised neurophysiological reserve in Alzheimer's than Lewy body dementia, at both group and individual levels. 


\section{Introduction}

Differential diagnosis of Alzheimer's disease (ADD), Parkinson's disease(PDD), and Lewy body dementia (DLB) is important as patients with DLB and PDD may be considerably more sensitive to adverse effects of neuroleptic (Ballard et al., 1998) and may exhibit faster disease progression (Olichney et al., 1998) and different responses to acetylcholinesterase inhibitors (Levy et al., 1994); furthermore, these diseases have at least in part different etiologies and might require specific disease-modifying regimens when available (Bhat et al., 2015; Karantzoulis and Galvin, 2013; McKeith et al., 2005).

In the light of the new international criteria (Albert et al., 2011; Dubois et al., 2014), $A D$ may be discriminated from PD and DLB by higher abnormalities in the cerebrospinal fluid (CSF) "A $\beta 42 /$ phospho-tau" ratio and deposition of $A \beta 42$ or tau in the brain as shown by positron emission tomography (PET) mapping. Other useful topographic biomarkers of $A D$ neurodegeneration are hypometabolism of the posterior cerebral cortex as revealed by ${ }^{18} \mathrm{~F}$-Fluorodeoxyglucose-positron emission tomography (FDG-PET) and hippocampus atrophy on magnetic resonance imaging (MRI), (Albert et al., 2011; Dubois et al., 2014; McKhan et al., 2011). PET or SPECT scan of dopamine transporter can also be used for the differential diagnosis between PDD and DLB on the one side and ADD on the other side (Zhu et al., 2014). Promising candidate topographic biomarkers are those derived from the analysis of resting state eyes-closed electroencephalographic (rsEEG) rhythms (Breslau et al., 1989; Briel et al., 1999; Giaquinto and Nolfe, 1986). The recording of rsEEG rhythms is non-invasive and costeffective. Markers of rsEEG rhythms may probe the neurophysiological "reserve" in patients with dementing disorders; the latter is defined as the residual ability of the brain to ensure (1) the synchronization of neural activity at different spatial scales and frequencies from small cellular populations to large regions and (2) the coordination of this synchronization across subcortical and cortical neural networks (Babiloni et al., 2016a). The neurophysiological reserve can thus be considered as one of the dimensions of the brain reserve (Stern, 2017). In this line, the assessment of the neurophysiological "reserve" in neurological patients can be based on two main classes of markers derived from rsEEG rhythms, namely the cortical neural "synchronization/desynchronization" at 
given frequency bands and "functional cortical connectivity", defined as the interdependence of cortical neural synchronization/desynchronization Intrahemisphericly and Interhemisphericly (Babiloni et al., 2015a). Practically, this connectivity can be computed from rsEEG rhythms recorded at electrode pairs or estimated in coupled cortical sources (Babiloni et al., 2015a).

Functional cortical connectivity might be especially relevant to understand the pathophysiological mechanisms underlying different dementing disorders, as human cognition is based on a coordinated neurotransmission within large-scale networks (D'Amelio and Rossini 2012; Pievani et al., 2011). Clinically, ADD typically presents with a major amnesic syndrome although there may be, less commonly linguistic, visuospatial, and visual disease variants (Dubois et al., 2014). PDD and DLB manifest with attentional, verbal, and executive cognitive deficits in association with motor manifestations such as bradykinesia, tremor, postural instability, and rigidity (Aarsland et al., 2003; Buter et al., 2008; Dubois and Pillon, 1997; Emre et al., 2007; Huber et al., 1989; Hughes et al., 2000; Levy et al., 2000; Walker et al., 2015; Wolters, 2001). Motor symptoms substantially precede cognitive deficits in PD but not DLB where the onset of motor symptoms is either at the same time as the cognitive deficits or emerges later. Furthermore, DLB is primarily characterized by visual hallucinations, REM sleep disturbances, and diurnal cognitive fluctuation (McKeith et al., 2005). It can be speculated that those different clinical phenotypes are related to different abnormalities in "synchronization/desynchronization" and "cortical functional connectivity" markers of rsEEG rhythms.

Concerning the "synchronization/desynchronization" markers, previous studies showed that compared normal healthy elderly (Nold) subjects, ADD patients are characterized by lower power density in posterior alpha $(8-12 \mathrm{~Hz})$ and beta $(13-30 \mathrm{~Hz})$ rhythms (Babiloni et al., 2006a; Dierks et al., 1993, 2000; Huang et al. 2000; Jelic et al., 2000; Jeong, 2004; Ponomareva et al., 2003). Furthermore, ADD patients exhibit higher power density in widespread delta $(<4 \mathrm{~Hz})$ and theta $(4-7 \mathrm{~Hz})$ rhythms (Brassen and Adler, 2003; Kogan et al., 2001; Onofrj et al., 2003; Reeves et al., 2002; Rodriguez et al., 2002; Valladares-Neto et al., 1995). Similarly, PDD patients demonstrate widespread high power density in delta and theta rhythms and some reduction of alpha power density (Bonanni et al., 2008; Bosboom et al., 2006, 2009; Caviness et al., 2016; Fünfgeld, 1995; Kamei et 
al., 2010; Melgari et al., 2014; Neufeld et al., 1988, 1994; Pugnetti et al., 2010; Serizawa et al., 2008; Soikkeli et al., 1991; Stam et al., 2006). DLB patients are characterized by diffuse and fluctuating delta and theta power density with some frequency spectra differences from those observed in PDD and ADD; these EEG features are described as a "supportive" biomarker in the clinical diagnostic guidelines (Andersson et al., 2008; Bonanni et al., 2008, 2015, 2016; Kai et al., 2005; McKeith et al., 2005, 2017; Onofrj et al., 2003; Walker et al., 2000a, b).

As far as the "functional cortical connectivity" markers are concerned, previous studies showed that compared with Nold subjects, ADD patients point to lower spectral coherence between electrode pairs in posterior alpha $(8-12 \mathrm{~Hz})$ and beta $(13-20 \mathrm{~Hz})$ rhythms (Adler et al., 2003; Anghinah et al., 2000; Besthorn et al., 1994; Dunkin et al., 1994; Fonseca et al., 2011, 2013; Jelic et al., 1997, 2000; Knott et al., 2000; Leuchter et al., 1987, 1992; Locatelli et al., 1998; Pogarell et al., 2005; Sloan et al., 1994). However, these effects are topographically variable being observed in temporo-parieto-occipital electrode pairs in some studies (Adler et al., 2003; Locatelli et al., 1998; Jelic et al., 1997, 2000) yet in other studies in frontocentral electrode pairs (Besthorn et al., 1994; Fonseca et al., 2013; Leucther et al., 1994). Furthermore, some studies report a coherence decrease of rsEEG rhythms at low frequencies, especially at central electrodes in the theta band (Adler et al., 2003; Knott et al., 2000). Other studies report an increase in widespread delta coherences (Babiloni et al., 2010; Locatelli et al., 1998) or a quite complex topographical pattern of coherence increases and decreases (Sankari et al., 2011). Moreover, studies using alternative techniques measuring rsEEG functional coupling show a decrement of synchronization likelihood in frontoparietal alpha rhythms in ADD and mild cognitive impairment patients compared with Nold subjects (Babiloni et al., 2004, 2006b). Finally, global beta phase lag index across all scalp electrode pairs was lower in ADD patients compared with Nold subjects (Stam et al., 2007).

The above rsEEG results have received some clinical validation. In $A D$ individuals, there are correlations between rSEEG coherences and scores of mini-mental state examination (MMSE), as a measurement of global cognitive status and language, memory, and constructional praxis (Fonseca et al., 2011, 2013). These correlations are negative for delta and theta bands and positive for alpha and beta bands (Fonseca et al., 
2011). Furthermore, there is an association between rsEEG coherence and periventricular white matter hyperintensities (PVHs) interpreted as due to impairment of neural transmission (Leuchter et al., 1992, 1994).

In PD individuals, abnormal functional cortical connectivity is consistently revealed by rsEEG coherence between electrode pairs. Compared to Nold subjects, PD patients show lower local intrahemispheric parietal alpha coherence (Moazami-Goudarzi et al., 2008). Furthermore, intrahemispheric cortico-cortical frontoparietal alpha and beta coherences are positively correlated with the severity of PD motor symptoms in the patients (Silberstein et al., 2005). Both L-dopa regimen and electrical stimulation of subthalamic nucleus reduce those coherences in association with an improvement of motor symptoms (Silberstein et al., 2005). Other evidence reveals a positive correlation between PD duration and beta coherence between rSEEG rhythms recorded in supplementary motor and primary motor areas (Pollok et al., 2013).

Concerning the relationship between functional cortical connectivity and cognition, PD patients with cognitive deficits demonstrate a positive correlation between decreased intrahemispheric frontoparietal alpha coherence and executive dysfunctions (Teramoto et al., 2016). Furthermore, PDD patients exhibit greater interhemispheric frontal alpha-beta and intrahemispheric fronto-occipital beta coherences than ADD patients do (Fonseca et al., 2013).

In line with ADD and PDD patients, DLB subjects show a derangement of functional cortical connectivity derived from rsEEG rhythms. Global delta and alpha coherences across all electrode pairs are reported as higher in DLB than ADD patients (Andersson et al., 2008). In contrast, global alpha phase lag index across all electrode pairs is lower in DLB than both ADD and Nold subjects (van Dellen et al., 2015). Furthermore, intrahemispheric fronto-temporo-central delta and theta coherences are higher in DLB than ADD patients, while temporo-centro-parieto-occipital beta (not alpha) coherences are lower in the former compared to the latter (Kai et al., 2005). Finally, posterior-toanterior directed information flow is lower in alpha in DLB patients and decreases in beta in ADD patients (Dauwan et al., 2016a).

The above measurements of rsEEG functional connectivity have been successfully used to discriminate ADD, PDD, and DLB individuals. Global delta and alpha coherences 
between electrode pairs allow for a classification accuracy (AUROC- curve) of DLB individuals compared with ADD and Nold subjects of 0.75-0.80 and 0.91-0.97 (e.g. $1=$ $100 \%$ of accuracy), respectively (Andersson et al., 2008). A complex step-wise procedure using 20 discriminant scalp rsEEG power density and coherences as an input to a statistical pattern recognition method shows a classification accuracy (AUROC curve) of 0.90 between ADD and Nold individuals as well as between ADD and PDD subjects (Engedal et al., 2015). Another recent study in relatively small populations of ADD, PDD/DLB, and frontotemporal dementia patients used 25 discriminant scalp rsEEG power density and functional cortical connectivity (i.e. Granger causality) variables as an input to support vector machine, reaching a classification accuracy of 1.0 (Garn et al., 2017). Paradoxically, another study combining quantitative rSEEG variables (including those of functional cortical connectivity) with neuropsychological, clinical, neuroimaging, cerebrospinal fluid, and visual EEG data reached "only" a classification accuracy of 0.87 in the discrimination between ADD, PDD, and DLB individuals (Dauwan et al., 2016b).

The inter-study variability of the mentioned results might be due to (1) the analysis of rsEEG data at scalp electrodes pairs and (2) the use of fixed frequency bands for all subjects, regardless the frequency "slowing" of rsEEG rhythms in dementia. To mitigate those potential confounding effects on "synchronization/desynchronization" markers, we have recently combined (1) a source estimation technique called exact lowresolution brain electromagnetic tomography (eLORETA; Pascual-Marqui, 2007a) and (2) an analysis of rsEEG rhythms based on the "individual alpha frequency peak" (IAF; Klimesch, 1996, 1999; Klimesch et al., 1998). With this approach, we tested the hypothesis that eLORETA source activity of scalp rsEEG rhythms might reflect different features of abnormal cortical neural synchronization/desynchronization in ADD, PDD, and DLB patients (Babiloni et al., 2017). To that aim, datasets in 42 PDD, 34 DLB, 42 ADD, and 40 Nold subjects were analyzed (demography, education, and the MMSE score did not differ between the patients' groups). Results are summarized in the following (Babiloni et al., 2017). The IAF exhibits a marked frequency slowing in the PDD and DLB groups and a moderate frequency slowing in the ADD group. Compared with Nold subjects, the three patients' groups show lower posterior alpha source activities. This effect is dramatic in the ADD group, marked in the DLB group, and moderate in the PDD group. The three patients' 
groups also exhibit higher occipital delta source activities. This effect is greatest in the PDD group, marked in the DLB group, and moderate in the ADD group.

Concerning the individual level, the posterior delta and alpha sources permitted good classification accuracies (AUROC curve) ranging $0.85-0.90$ between the Nold subjects and patients as well as between ADD and PDD patients (Babiloni et al., 2017). Those findings unveiled different spatial and frequency features of the cortical neural synchronization/desynchronization underpinning brain arousal in quiet wakefulness in $A D D, P D D$, and DLB patients where the DLB group showed features in between the ADD and PDD groups.

Keeping in mind those findings and considerations, the present retrospective exploratory study re-analyzed that original rsEEG database used in the stude of Babiloni and colleagues (2017) to derive complementary "functional cortical connectivity" markers. We compared the intrahemispheric and interhemispheric lagged linear connectivity between cortical sources of rsEEG rhythms in Nold, ADD, PDD, and DLB subjects. The comparison was made both at the group and the individual level. The core hypothesis was that at both levels, "functional cortical connectivity" markers were globally more altered in ADD patients whose disease has been considered as a cortical "disconnection syndrome" (Besthorn et al., 1994; Bokde et al., 2009; Dunkin et al., 1995; Leuchter et al., 1994; Reuter-Lorenz and Mikels, 2005; Teipel et al., 2016).

\section{Materials and Methods}

Details on the subjects, diagnostic criteria, rsEEG recording, and preliminary data analysis were reported in the reference paper (Babiloni et al., 2017). In the following sections, we provide a short description of those methodological procedures for readers' convenience.

\section{Subjects and diagnostic criteria}

We used the rSEEG data of an international archive, formed by clinical, neuropsychological, and electrophysiological data in 40 Nold, 42 ADD, 42 PDD, and 34 DLB subjects. The four groups (i.e. PDD, ADD, DLB, and Nold) were carefully matched for age, gender, and education. The three groups of patients with dementia were also carefully 
matched for the MMSE score (Folstein et al. 1975). Table 1 reports details of the above variables.

\section{Insert here Table 1}

Probable ADD was diagnosed according to the criteria of the Diagnostic and Statistical Manual of Mental Disorders, fourth edition (DSM-IV-TR; American Psychiatric Association) and the National Institute of Neurological Disorders and Stroke-Alzheimer Disease and Related Disorders (NINCDS-ADRDA) working group (McKhann et al., 1984).

The ADD patients underwent general medical, neurological, and psychiatric assessments. They were also rated on some standardized clinical scales that included MMSE (Folstein et al., 1975), clinical deterioration rate (CDR; Hughes et al., 1982), 15-item geriatric depression scale (GDS; Yesavage et al., 1983), Hachinski Ischemic Score (HIS; Rosen et al., 1980), and Instrumental Activities of Daily Living scale (IADL; Lawton and Brodie, 1969). Neuroimaging diagnostic procedures (MRI) and laboratory analyses were carried out to exclude other causes of progressive or reversible dementias, in order to form a relatively homogenous ADD patient group. Computed Tomography (CT) was performed in those patients with contraindications to MRI.

Inclusion criteria were as follows: (1) objective impairment on neuropsychological evaluation, as defined by performances 1.5 standard deviations (SD) from the mean value for the age- and education-matched controls in at least two cognitive domains; (2) clinical dementia rating score higher than 0.5 ; and (3) abnormal activities of daily living as attested by the history and evidence of independent living.

Exclusion criteria included any evidence of (1) frontotemporal dementia, diagnosed according to criteria of Lund and Manchester Groups (1994), (2) vascular dementia, diagnosed according to NINDS-AIREN criteria (Roman et al., 1993), (3) extrapyramidal syndromes, (4) reversible dementias (including pseudodementia of depression), and (5) Lewy body disease associated dementia. A battery of neuropsychological tests assessed general cognitive performance in the domains of memory, language, executive function/attention, and visuoconstruction abilities (for details see Babiloni et al., 2017). Concerning psychoactive medications, most of the enrolled ADD patients (89\%) followed a long-term treatment with standard daily doses of acetylcholinesterase inhibitors (AChEls ; e.g., donepezil 5-10 mg/die or rivastigmine 
$3 \mathrm{mg} /$ die; galantamine $16-36 \mathrm{mg} / \mathrm{die}$ ). About $2 \%$ received $\mathrm{N}-$ Methyl-D-aspartate receptor (NMDAR) antagonists (e.g., memantine). About 24\% non-regularly took antidepressant or sedatives (e.g., fluoxetine, benzodiazepines) drugs.

The diagnosis of PD was based on a standard clinical assessment of tremor, rigidity, and bradykinesia (Gelb et al., 1999). As measures of severity of motor disability, the Hoehn and Yahr stage (Hoehn and Yahr, 1967) and the Unified Parkinson Disease Rating Scale-III (UPDRS-III; Fahn and Elton, 1987) for extrapyramidal symptoms were used. A diagnosis of PDD was given to the patients with a history of dementia (inclusion criteria as for ADD) preceded by a diagnosis of PD for at least 12 months.

On the basis of clinical features and neuroradiological findings, exclusion criteria for PDD included the following forms of parkinsonism: (1) DLB (McKeith et al., 1996), (2) secondary parkinsonism, including drug-induced parkinsonism, (3) cerebrovascular parkinsonism, and (4) atypical parkinsonism with absent or minimal responses to antiparkinsonian drugs.

All PDD patients underwent a battery of clinical scales including the Neuropsychiatric Inventory (NPI; Cummings et al., 1994), the scale for the assessment of Behavioral and Psychological Symptoms of Dementia (BPSD), the MMSE, the Dementia Rating Scale-2 (DRS-2; Jurica et al., 2001), the Epworth Sleepiness Scale (ESS) to estimate subjective sleep disturbances, and the Alzheimer's Disease Cooperative Study for the Activities of Daily Living (ADCS-ADL). All PDD subjects also underwent a battery of neuropsychological tests (for details see Babiloni et al., 2017). Concerning psychoactive medications, most of the enrolled PDD patients (79\%) followed a treatment with standard doses of dopamine agonists (levodopa, carbidopa, entacapone, pramipexole, apomorphine, tolcapone, rasagiline or rotigotine). About $45 \%$ assumed AChEls (rivastigmine, donepezil, galantamine) and about 5\% received NMDAR antagonists (memantine). Furthermore, about $42 \%$ regularly took anti-depressant (selective serotonin reuptake inhibitor: sertaline, citalopram, paroxetine; monoamine oxidase inhibitor: selegiline; noradrenergic and specific serotonergic antidepressant: mirtazapine; serotonin antagonist and reuptake inhibitor: trazodone; serotonin-norepinephrine reuptake inhibitor: venlafaxine). Finally, about $8 \%$ of them took benzodiazepine sedatives 
(lorazepam, clonazepam) and $37 \%$ of them took anti-psychosis (quetiapine, clozapine, aripiprazole).

Dementia was diagnosed in the DLB patients as for the ADD and PDD patients (see above inclusion and exclusion criteria). The diagnosis of probable DLB was carried out in agreement with the consensus guidelines by McKeith and colleagues (2005). Concerning the detection of the core and suggestive features of DLB, the NPI item-2 investigated the occurrence frequency and the severity of hallucinations (Cummings et al., 1994). Frontal Assessment Battery (FAB; Dubois et al., 2000) and Clinician Assessment of Fluctuations (Walker et al., 2000a) were included to investigate, respectively, the severity of frontal dysfunctions and the presence and severity of cognitive fluctuations. UPDRS-III (Fahn and Elton, 1987) assessed the presence and severity of extrapyramidal signs. The presence or absence of rapid eye movement (REM) sleep behavior disorder (RBD) was determined according to minimal International Classification of Sleep Disorders criteria (1992). All DLB subjects also underwent a battery of neuropsychological tests (for details see Babiloni et al., 2017). Concerning psychoactive medications, half of the enrolled DLB patients (50\%) followed a treatment with standard doses of dopamine agonist (levodopa, carbidopa, entacapone). About $25 \%$ assumed AChEls (rivastigmine) and about $13 \%$ received NMDAR antagonists (memantine). Furthermore, about 38\% regularly took anti-depressant (SSRI: citalopram, paroxetine). Finally, about $13 \%$ of them took benzodiazepine sedatives (lorazepam) and most of them (63\%) took anti-psychosis (quetiapine, clozapine) drugs.

In all ADD, PDD and DLB patients, drugs were suspended for about $24 \mathrm{~h}$ before EEG recordings. This did not insure a complete washout of the drug -longer periods would not have been applicable for obvious ethical reasons-, but made it comparable the drug condition in the ADD, PDD and DLB patients.

All Nold subjects underwent a cognitive screening (including MMSE and GDS) as well as physical and neurological examinations to exclude any dementia or major cognitive deficit or psychiatric disorder.

\section{rSEEG recordings and preliminary data analysis}

The rsEEG data were recorded in the morning while subjects kept their eyes closed in a relaxed state, not moving or talking. About five minutes of rSEEG data were recorded 
(128 Hz or higher sampling rate, with related antialiasing bandpass between $0.01 \mathrm{~Hz}$ and $100 \mathrm{~Hz}$ ) from 19 scalp electrodes positioned according to the 10-20 System (i.e. Fp1, Fp2, F7, F3, Fz, F4, F8, T3, C3, Cz, C4, T4, T5, P3, Pz, P4, T6, O1, and O2). A ground electrode was located in the frontal region. Electrodes impedances were kept below 5 Kohm. Horizontal and vertical electro-oculographic activities $(0.3-70 \mathrm{~Hz}$ bandpass) were also recorded to monitor blinking and eye movements. Table 1 in the Supplementary material reports details about sampling rates, time constants, and digital EEG systems used in all Recording Units of the present international Consortium. Figure 1 show representative EEG waveforms (10 s) on Fz and Pz scalp electrodes for Nold, ADD, PDD, and DLB subjects. These subjects were carefully selected to represent the general features of EEG waveforms in the groups of individuals investigated in the present study.

\section{Insert here Figure 1}

The rsEEG data were divided into segments of 2 seconds and analyzed off-line. The epochs affected by any physiological (ocular/blinking, muscular, head movements) or non-physiological (bad contact electrode-scalp) artifacts were preliminarily identified by an automatic computerized procedure (Moretti et al., 2003). Furthermore, two independent experimenters manually checked and (dis)confirmed the artifact-free rsEEG epochs, before successive analyses. Specifically, they controlled for the presence of ocular and blinking artifacts based on electro-oculographic signals, while muscular and head artifacts were recognized by analyzing EEG signals. Moreover, head artifacts were detected by a sudden and great increase in amplitude of slow EEG waves in all scalp electrodes. Finally, muscle artifacts were recognized observing the effects of several frequency bandpass filters in different ranges and by the inspection of EEG power density spectra. Muscle tension is related to unusually high and stable values of EEG power density from 30 to $100-150 \mathrm{~Hz}$, which contrast with the typical declining trend of EEG power density from $25 \mathrm{~Hz}$ onward. As a result, the two experimenters selected 118 ( \pm 5 SE) artifact-free EEG epochs in the Nold group, 106 ( $\pm 7 \mathrm{SE}$ ) in the ADD group, 84 ( $\pm 5 \mathrm{SE}$ ) in the PDD group and 105 ( \pm 5 SE) in the DLB group. The artifact-free epochs showed the same proportion of the total amount of rsEEG recorded in all groups (> 80\%).

A standard digital FFT-based power spectrum analysis (Welch technique, Hanning 
windowing function, no phase shift) computed the power density of scalp rsEEG rhythms with $0.5 \mathrm{~Hz}$ of frequency resolution. The frequency bands of interest were individually identified based on the following frequency landmarks: the transition frequency (TF) and the IAF. In the EEG power density spectrum, the TF marked the transition frequency between the theta and alpha bands, defined as the minimum of the rsEEG power density between 3 and $8 \mathrm{~Hz}$ (between the delta and the alpha power peak). Instead, the IAF was defined as the maximum power density peak between 6 and $14 \mathrm{~Hz}$. These frequency landmarks were originally introduced in the individual frequency analysis of EEG activity by Dr. Wolfgang Klimesch (Klimesch, 1996, 1999 and Klimesch et al., 1998). Of note, the relative individual frequency bands are useful to account for the "slowing" in frequency of rsEEG rhythms due to dementing disorders. However, they do not provide a clear cut threshold to discriminate a patient with a dementing disorder from an Nold individual with an innate slowing of that frequency in rsEEG rhythms.

The TF and IAF were computed for each subject involved in the study. Based on the TF and IAF, we estimated the individual delta, theta, and alpha bands as follows: delta from TF $-4 \mathrm{~Hz}$ to TF $-2 \mathrm{~Hz}$, theta from TF $-2 \mathrm{~Hz}$ to TF, low-frequency alpha (alpha 1 and alpha 2) from TF to IAF, and high-frequency alpha (or alpha 3) from IAF to IAF $+2 \mathrm{~Hz}$. Specifically, the individual alpha 1 and alpha 2 bands were computed as follows: alpha 1 from TF to the frequency midpoint of the TF-IAF range and alpha 2 from that midpoint to IAF. The other bands were defined based on the standard fixed frequency ranges used in the reference study (Babiloni et al., 2017): beta 1 from 14 to $20 \mathrm{~Hz}$, beta 2 from 20 to 30 $\mathrm{Hz}$, and gamma from 30 to $40 \mathrm{~Hz}$.

\section{Estimation of functional connectivity of rsEEG cortical sources}

The eLORETA freeware was used to estimate the functional cortical connectivity from rsEEG rhythms (Pascual-Marqui, 2007a). Specifically, we used the toolbox called lagged linear connectivity (LLC; Pascual-Marqui et al., 2011). LLC provides linear measurements (from now on "LLC solutions") of the statistical interdependence of pairs of eLORETA cortical source activations estimated from scalp rsEEG rhythms at a given frequency. The procedure provides LLC solutions between all combinations of voxels in the cortical source space of eLORETA (Pascual-Marqui et al., 2011). In its practical use, 
researchers can average those LLC solutions across eLORETA voxels for pairs of regions of interest (ROIs).

Noteworthy, LLC solutions are estimated by removing the zero-lag instantaneous phase interactions between rSEEG cortical sources estimated by eLORETA freeware. The rationale is that these zero-lag phase interactions could be affected by instantaneous physical propagation of neural ionic currents from a given source to all the others merely due to head volume conductor effects (Pascual-Marqui, 2007b). Furthermore, the LLC solutions took into account measures of interdependence among multivariate rsEEG time series, thus partially mitigating the head volume conduction component of the so-called "common drive/source" effect of a "third" source on the LLC solutions estimated between two sources of interest (Pascual-Marqui, 2007c). However, the LLC solutions are intrinsically "bivariate" measuremens that may not take into account for the "common drive/source" due to the propagation of actions potentials along nerves to two (or more) target cortical neural populations generating EEG signals. In the case of a "common drive/source", the EEG signals generated from these target populations are expected to be delayed one in respect to another because of different axon path lengths. As a result, there may be phase differences between them accompanied with high coherence values not related to a "true" functional connection.

For each subject and frequency band of interest (i.e. delta, theta, alpha 1, alpha 2, alpha 3 , beta 1 , beta 2 , and gamma), LLC solutions were computed for 5 ROIs, namely frontal, central, parietal, occipital, and temporal lobes in the eLORETA cortical source space (Pascual-Marqui, 2007a).

For the interhemispheric analysis, the LLC solutions were calculated between all voxels of the mentioned ROIs of each hemisphere with the homologous ones of the other hemisphere. The LLC solutions for all voxels of a given pair of ROIs were averaged. For each frequency band of interest, the following 5 interhemispheric LLC solutions were computed: frontal (i.e. frontal left - frontal right LLC), central (i.e. central left - central right LLC), parietal (i.e. parietal left - parietal right LLC), occipital (i.e. occipital left occipital right LLC), and temporal (i.e. temporal left - temporal right LLC).

For the intrahemispheric analysis, the LLC solutions were computed for all voxels of a particular ROI with all voxels of another ROI of the same hemisphere. The LLC 
solutions for all voxels of a given pair of ROls were averaged. This operation was repeated for the left and the right hemisphere, separately. In particular, for each frequency band of interest and the left hemisphere, the following 5 left intrahemispheric LLC solutions were computed: (1) frontal (i.e. mean among left frontal - central, left frontal - parietal, left frontal - temporal, and left frontal - occipital LLC), (2) central (i.e. mean among left central - frontal, left central - parietal, left central - temporal, and left central - occipital LLC), (3) parietal (i.e. mean among left parietal - frontal, left parietal - central, left parietal temporal, and left parietal - occipital LLC), (4) occipital (i.e. mean among left occipital frontal, left occipital - central, left occipital - parietal, and left occipital - temporal LLC), and 5) temporal (i.e. mean among left temporal - frontal, left temporal - central, left temporal - parietal , and left temporal - occipital LLC). The same procedure was repeated for the right hemisphere.

Table 2 reports the Talairach coordinates of the centroid voxel for the left and right frontal, central, parietal, occipital, and temporal ROls

\section{Insert here Table 2}

\section{Statistical analysis of the LLC of rSEEG cortical sources}

The main statistical session was performed by the commercial tool STATISTICA 10 (StatSoft Inc., www.statsoft.com) to test the hypothesis that the functional cortical connectivity as revealed by the eLORETA LLC solutions between rSEEG source pairs (hereinafter LLC solutions) might differ between the ADD, PDD, and DLB groups, using the Nold group as a control reference. To this aim, two ANOVAs were computed using the eLORETA LLC solutions as dependent variables $(p<0.05)$.

The first ANOVA tested the differences of interhemispheric LLC solutions between the ADD, PDD, and DLB groups using the Nold group as a control reference. The ANOVA factors were Group (Nold, ADD, PDD, and DLB), Band (delta, theta, alpha 1, alpha 2, alpha 3 , beta 1 , beta 2 , and gamma), and ROI (frontal, central, parietal, occipital, and temporal).

The second ANOVA also tested the differences of intrahemispheric LLC solutions between the ADD, PDD, and DLB groups using the Nold group as a control reference. The ANOVA factors were Group (Nold, ADD, PDD, and DLB), Hemisphere (left and right), Band 
(delta, theta, alpha 1 , alpha 2 , alpha 3 , beta 1 , beta 2 , and gamma), and ROI (frontal, central, parietal, occipital, temporal, and limbic).

Individual TF and the IAF values were used as covariates. Mauchly's test evaluated the sphericity assumption. The degrees of freedom were corrected by the GreenhouseGeisser procedure when appropriate $(p<0.05)$.

Duncan test was used for post-hoc comparisons $(p<0.05)$. The planned post-hoc testing evaluated the primary hypothesis about the differences in the LLC solutions between the ADD, PDD, and DLB groups, using the Nold group as a control reference. Specifically, we tested the following predictions: (1) a statistically significant interaction effect including the factor Group ( $p<0.05)$; (2) a post-hoc test indicating statistically significant differences in the LLC solutions between the ADD, PDD, DLB, and Nold groups (Duncan test, $p<0.05$ ). The input data for the mentioned statistical analyses were controlled by the Grubbs test $(p<0.0001)$ for the presence of outliers in the distribution of the LLC solutions.

As an exploratory statistical analysis at the individual level, Spearman test evaluated the correlation between the MMSE score and LLC solutions showing statistically significant differences between the Nold and the patients' groups $(p<0.05)$. The correlation analysis was performed considering all Nold, ADD, PDD, and DLB individuals as a whole group for two reasons. On the one hand, the hypothesis was that LLC solutions from rSEEG cortical sources were correlated with the global cognitive status in seniors in general, namely including cases with both normal and impaired cognitive functions. On the other hand, the correlation study would have had a low statistical sensitivity if performed only in the separate groups, due to the very limited scatter of the MMSE scores within a given group (e.g. in Nold subjects, MMSE score can just assume discrete values of 30,29 , and 28 ). To take into account the inflating effects of repetitive univariate tests, the statistical threshold was determined based on the Bonferroni correction at $p<$ 0.05 .

Accuracy of the discrimination between the Nold, $A D D, P D D$, and $D L B$ individuals based on eLORETA LLC solutions 
eLORETA LLC solutions showing statistically significant differences $(p<0.05$ ) among the four groups in the above ANOVAs (i.e. effects of the factor Group and Duncan post-hoc) were used as discriminant variables for the classification of the Nold subjects and the demented patients of each pathological group (i.e. Nold vs. ADD, Nold vs. DLB, and Nold vs. PDD) and between the patients of pairs of the pathological groups (i.e. ADD vs. DLB, ADD vs. PDD, and DLB vs. PDD). These classifications were performed by GraphPad Prism software (GraphPad Software, Inc., California, USA) using its implementation of ROC curves (DeLong et al., 1988). The following indexes measured the results of the binary classifications: (1) Sensitivity. It measures the rate of the cases (i.e. patients with dementia in the classifications of those patients and Nold subjects) who were correctly classified as cases (i.e. "true positive rate" in the signal detection theory); (2) Specificity. It measures the rate of the controls (i.e. Nold subjects in the classifications of those subjects and patients with dementia) who were correctly classified as controls (i.e. "true negative rate" in the signal detection theory); (3) Accuracy. It is the mean between the sensitivity and specificity weighted for the number of cases and controls; and (4) AUROC curve. For the sake of brevity, the AUROC curve was used as a major reference index of the global classification accuracy.

\section{Results}

\section{Comparison of TF and IAF}

Table 3 reports the mean values of TF and IAF for the 4 groups (i.e., Nold, ADD, PDD, and DLB), together with the results of the statistical comparisons between the groups (ANOVA). The mean TF was $5.9 \mathrm{~Hz}( \pm 0.2 \mathrm{SE})$ in the Nold, $5.4 \mathrm{~Hz}( \pm 0.2 \mathrm{SE})$ in the $A D D, 4.8 \mathrm{~Hz}( \pm 0.1 \mathrm{SE})$ in the PDD, and $4.9 \mathrm{~Hz}( \pm 0.1 \mathrm{SE})$ in the DLB group. The mean IAF was $9.0 \mathrm{~Hz}( \pm 0.2 \mathrm{SE})$ in the Nold, $8.0 \mathrm{~Hz}( \pm 0.3 \mathrm{SE})$ in the ADD, $7.3 \mathrm{~Hz}( \pm 0.2 \mathrm{SE})$ in the PDD, and $7.2 \mathrm{~Hz}( \pm 0.2 \mathrm{SE})$ in the DLB group.

The statistical analysis of those values showed the following results. There was a main effect of the ANOVA using the TF as a dependent variable and the factor Group ( $F=$ $10.4, p<0.0001)$. Duncan post-hoc test showed that the mean TF was greater in the Nold than the ADD $(p<0.05)$, the PDD $(p<0.00001)$, and the group DLB $(p<0.00005)$. 
Furthermore, the mean TF was higher in the ADD than the PDD $(p<0.05)$ and the DLB group $(p<0.05)$.

Another result was the main effect of the ANOVA using the IAF as a dependent variable and the factor Group $(F=14.9, p<0.00001)$. Duncan post-hoc test showed that the mean IAF was greater in the Nold than the ADD $(p<0.001)$, the PDD $(p<0.00001)$, and the DLB group ( $p<0.000005$ ). The mean IAF was also higher in the ADD than the PDD $(p<0.05)$ and the DLB group $(p<0.01)$.

As a remark, 9 ADD, 2 PDD, and 5 DLB patients exhibited asymptotic rsEEG power spectra, without any alpha power peak. Therefore, they were not considered for the statistical analysis of IAF. For the analysis of LLC solutions, the frequency bands from delta to alpha were determined based on the group mean values of IAF.

\section{Insert Table 3}

\section{Comparison of eLORETA interhemispheric LLC solutions}

Figure 2 shows mean values ( \pm standard error mean, SE) of the interhemispheric LLC solutions relative to a statistically significant ANOVA interaction effect $(F=3.3, p<$ 0.0001) among the factors Group (Nold, ADD, PDD, and DLB), Band (delta, theta, alpha 1, alpha 2 , alpha 3 , beta 1 , beta 2 , and gamma), and ROI (frontal, central, parietal, occipital, and temporal). Here the LLC solutions reflect the statistical interdependence of pairs of homologous eLORETA cortical sources between the two hemispheres, estimated from scalp rsEEG rhythms at the frequency bands of interest. In Figure 2, the profile and magnitude of the interhemispheric LLC solutions clearly differed across the ROIs and frequency bands within and between the Nold, ADD, PDD, and DLB groups, exploiting spatial and frequency information contents of the methodological approach.

In the Nold group as a physiological reference, dominant values of interhemispheric LLC solutions were observed in temporal (maximum), occipital, and parietal alpha 2 and alpha 3 sources. Low values of interhemispheric LLC solutions were found in the widespread delta, theta, and alpha 1 sources. The LLC solutions in beta 1, beta 2 , and gamma sources were close to zero, possibly confirming the lack of ocular, head, and muscular artefacts in the EEG data. Summarizing, the Nold group was 
characterized by a prominent interhemispheric functional connectivity between posterior cortical sources from moderate to high-frequency alpha rhythms.

Compared with the Nold group, the three patients' groups (i.e. ADD, PDD, and DLB) showed a similar spatial and frequency profile of interhemispheric LLC solutions but a lower magnitude in the alpha range (beta 1, beta 2 , and gamma sources were close to zero as in the Nold group). Specifically, there was a substantial decrease of the interhemispheric LLC solutions in parietal, occipital, and temporal alpha 2 and alpha 3 sources, which was maximum in the ADD group. Furthermore, interhemispheric LLC solutions in delta sources generally showed a diffuse and very slight increase in the patients' groups. The only exception was a more consistent increase of LLC solutions in delta sources in the ADD group.

Duncan planned post-hoc testing revealed that the discriminant LLC pattern ADD < DLB $<$ PDD $<$ Nold was fitted only by the occipital and temporal alpha 3 sources $(p<0.05$ to 0.000001$)$, which were decreased dramatically in the ADD group $(p<0.000001)$, markedly in the DLB group ( $p<0.000001)$, and moderately in the PDD group $(p<0.005)$ compared with the Nold group. This interhemispheric effect was the most effective in differentiating the three neurodegenerative dementing disorders at the group level.

Duncan planned post-hoc testing revealed that the discriminant LLC pattern ADD < DLB $<$ PDD $<$ Nold was fitted only by the occipital and temporal alpha 3 sources $(p<0.05$ to 0.000001$)$, which were decreased dramatically in the ADD group $(p<0.000001)$, markedly in the DLB group $(p<0.000005)$, and moderately in the PDD group $(p<0.01)$ compared with the Nold group. This interhemispheric effect was the most effective in differentiating the three neurodegenerative dementing disorders at the group level.

Another finding was the discriminant LLC pattern ADD < DLB and PDD < Nold, fitted only by the occipital and temporal alpha 2 sources ( $p<0.005$ to 0.000001 ). Those discriminant LLC solutions pointed to a dramatic reduction in the ADD group ( $p<$ $0.000001)$ and a marked reduction in both DLB and PDD groups $(p<0.005)$ when compared to the Nold group. This interhemispheric effect was the most effective in differentiating $A D D$ vs. DLB/PDD at the group level.

The discriminant LLC pattern ADD and DLB $<$ PDD $<$ Nold was fitted only by the parietal alpha 2 and alpha 3 sources ( $p<0.005$ to 0.000005 ). Those discriminant LLC 
solutions indicated a dramatic reduction in the ADD and DLB groups $(p<0.000005)$ and a marked reduction in the PDD group $(p<0.0001)$ in relation to the Nold group. This interhemispheric effect was the most effective in differentiating ADD/DLB vs. PDD at the group level.

Finally, interhemispheric LLC solutions in delta sources showed only a unique effect in the occipital delta sources, namely greater solutions in the ADD than the Nold and PDD groups $(p<0.05)$.

\section{Insert here Figure 2}

\section{Comparison of eLORETA intrahemispheric LLC solutions}

Figure 3 plots mean values ( \pm SE) of the intrahemispheric LLC solutions relative to a statistically significant ANOVA interaction effect $(F=3.2, p<0.0001)$ among the factors Group (Nold, ADD, PDD, and DLB), Band (delta, theta, alpha 1, alpha 2, alpha 3, beta 1, beta 2, and gamma), and ROI (frontal, central, parietal, occipital, and temporal). Noteworthy, there was no effect of the factor Hemisphere (left and right), pointing to a substantial symmetry of the intrahemispheric LLC solutions on the left and the right side. In Figure 3, the profile and magnitude of the intrahemispheric LLC solutions clearly differed across the ROls and frequency bands within and between the Nold, ADD, PDD, and DLB groups.

In the Nold group as a reference, dominant values of intrahemispheric LLC solutions were observed in temporal (maximum), occipital, and parietal alpha 2 and alpha 3 sources, while moderate values were found in central and frontal alpha 2 and alpha 3 sources. Low interhemispheric LLC solutions were found in the delta, theta, and alpha 1 sources in all ROls. As for the interhemispheric LCC solutions, the intrahemispheric LLC solutions in beta 1 , beta 2 , and gamma sources were close to zero, possibly confirming the lack of ocular, head, and muscular artefacts in the EEG data. On the whole, the Nold group was characterized by a prominent intrahemispheric functional connectivity in widespread cortical sources of moderate to high-frequency alpha rhythms.

As for the intrahemispheric LLC solutions, the three patients' groups (i.e. ADD, PDD, and DLB) showed a similar spatial and frequency profile of intrahemispheric LLC solutions but a lower magnitude in the alpha range (beta 1 , beta 2 , and gamma sources 
were close to zero as in the Nold group). Specifically, there was a substantial decrease of the intrahemispheric LLC solutions in central, parietal, occipital, and temporal alpha 2 and alpha 3 sources, which was maximum in the ADD and DLB groups. Furthermore, intrahemispheric LLC solutions in delta sources generally showed a diffuse but slight increase in the patients' groups. The only exception was a more consistent increase in those solutions in temporal, parietal, and occipital delta sources in the ADD group.

In contrast to the interhemispheric LLC solutions, Duncan planned post-hoc testing revealed no significant discriminant LLC pattern ADD $<$ DLB $<$ PDD $<$ Nold $(p>0.05)$ for the intrahemispheric LLC solutions, mostly due to the similar profiles of the latter in the ADD and DLB groups.

An interesting finding was the discriminant LLC pattern ADD and DLB $<$ PDD $<$ Nold fitted by many sources, namely the central, parietal, temporal, and occipital alpha 2 and alpha 3 sources ( $p<0.0005$ to $<0.000001$ ). These discriminant intrahemispheric LLC solutions showed a dramatic reduction in the ADD and DLB groups $(p<0.000001)$, while the decrease was moderate in the PDD group $(p<0.00005)$ as compared to the Nold group. This intrahemispheric effect was the most efficient in disentangling ADD/DLB and PDD at the group level.

Another finding was the discriminant intrahemispheric LLC pattern ADD $<$ DLB and PDD $<$ Nold, fitted only by the frontal alpha 2 sources ( $p<0.05$ to 0.00001 ). These discriminant LLC solutions exhibited a very marked reduction in the ADD group $(p<$ $0.00001)$, while the decrease was moderate in the DLB and PDD groups $(p<0.05)$. This was the only intrahemispheric effect differentiating ADD and DLB at the group level.

Finally, intrahemispheric LLC solutions in the temporal delta sources were higher in the ADD than the Nold, PDD, and DLB groups ( $p<0.05$ to 0.005$)$. In addition, intrahemispheric LLC solutions in the frontal, central, parietal, and occipital delta sources were higher in the ADD than the Nold group ( $p<0.01$ to 0.0001 ).

\section{Insert here Figure 3}

A control statistical analysis was performed to verify that the above discriminant LLC solutions were not merely due to some outliers. To this aim, the Grubbs' test ( $p<$ 0.0001 ) tested the presence of outliers in the data of the four groups (i.e. Nold, ADD, DLB, 
and PDD). The analysis was performed for the 6 discriminant interhemispheric LLC solutions in the alpha sources (i.e. parietal, occipital, and temporal alpha 2; parietal, occipital, and temporal alpha 3) and the 9 discriminant intrahemispheric LLC solutions in those sources (i.e. frontal, central, parietal, occipital, and temporal alpha 2; central, parietal, occipital, and temporal alpha 3). Furthermore, this analysis was also performed for 1 interhemispheric LLC solution in the occipital delta sources and 5 intrahemispheric LLC solutions in the frontal, central, parietal, occipital, and temporal delta sources. No outlier was found in any group (see Figure 4 and Figure 5), thus confirming the results of the main statistical analysis.

\section{Insert here Figure 4 and Figure 5}

Correlation of LLC solutions and MMSE scores across Nold, $A D D, D L B$, and PDD individuals

As a first exploratory analysis at the individual level, Spearman test evaluated the correlation between the MMSE score, and 21 LLC solutions showing statistically significant differences between the Nold and the patients' groups $(p<0.05)$. These LLC solutions are listed in the following: (1) interhemispheric LLC solutions in the occipital delta sources; (2) interhemispheric LLC solutions in the parietal, occipital, and temporal alpha 2 sources; (3) interhemispheric LLC solutions in the parietal, occipital, and temporal alpha 3 sources; (4) intrahemispheric LLC solutions in the frontal, central, parietal, occipital, and temporal delta sources; (5) intrahemispheric LLC solutions in the frontal, central, parietal, occipital, and temporal alpha 2 sources; and (6) intrahemispheric LLC solutions in the central, parietal, occipital, and temporal alpha 3 sources. To take into account the inflating effects of repetitive univariate tests, the statistical threshold was set at $p<0.0023$ to obtain the Bonferroni correction at $p<0.05$.

A positive correlation was found between the interhemispheric LLC solutions in the temporal alpha 3 sources and the MMSE scores $(r=0.24, p<0.002)$. The lower the interhemispheric LLC solutions, the lower the MMSE score. Similarly, the intrahemispheric LLC solutions in the central $(r=0.26, p<0.001)$, parietal $(r=0.26, p<0.001)$, and occipital $(r=0.26, p<0.002)$ alpha 3 sources were correlated with the MMSE scores. The lower the intrahemispheric LLC solutions, the lower the MMSE scores. Figure 6 shows the 
scatterplots of those 4 LLC solutions showing statistically significant correlations $(p<0.05$ corrected).

The LCC solutions in the delta sources showed only marginal statistical effects. There was a significant negative correlation between the interhemispheric occipital delta sources and the MMSE score $(r=-0.21 ; p=0.005)$. The higher the interhemispheric LLC solutions in those sources, the lower the MMSE score.

As a control analysis, the same correlation test was performed for any single group considered separately. No statistically significant result $(p>0.05)$ was observed, possibly due to the limited range of the MMSE score within the single groups.

\section{Insert here Figure 6}

Classification among Nold, $A D D, P D D$, and DLB individuals based on the discriminant $L L C$ solutions

As a second exploratory analysis at the individual level, the above 15 LLC solutions showing statistically significant differences between the Nold and the three patients' groups ( $p<0.05$ ) were used as an input to the computation of the AUROC curves. Additionally, this analysis was also performed for 1 interhemispheric LLC solution in the occipital delta sources and 5 intrahemispheric LLC solutions in the frontal, central, parietal, occipital, and temporal delta sources for the classification of the Nold and ADD individuals. This second exploratory analysis tested the ability of those LLC solutions in the classification of (1) Nold subjects vs. patients and (2) patients of two paired pathological groups (i.e. ADD vs. DLB, ADD vs. PDD, DLB vs. PDD). Maximum classification accuracies were obtained in the classification between the Nold subjects and ADD patients and between the Nold and DLB patients. Table 4 reports the results in detail.

The classification between Nold vs. ADD individuals showed that all 15 LLC solutions in the alpha sources overcome the threshold of 0.7 of the AUROC curve (i.e. the inferior limit of a "moderate" classification rate). Among these LLC solutions, the interhemispheric temporal alpha 3 LLC solutions reached the following best classification rate (Figure 7 top): a sensitivity of $78.6 \%$, a specificity of $77.5 \%$, an accuracy of $78.1 \%$, and 0.84 of the AUROC curve. Among the LLC solutions of the delta sources, the only interhemispheric occipital delta LLC solutions reached the threshold of 0.7 of the AUROC curve. It was 
observed a sensitivity of $61.9 \%$, a specificity of $77.5 \%$, an accuracy of $69.8 \%$, and 0.70 of the AUROC curve.

Concerning the classification of the Nold vs. PDD individuals, only the following 2 LLC solutions in alpha sources overcome the threshold of 0.7 of the AUROC curve (Table 4): interhemispheric LLC solutions in the temporal alpha 2 and alpha 3 sources. Among these LLC solutions, the interhemispheric LLC solutions in the temporal alpha 2 sources reached the following best classification rate (Figure 7 , middle): a sensitivity of $82.3 \%$, a specificity of $70 \%$, an accuracy of $76.2 \%$, and 0.75 of the AUROC curve.

Regarding the classification of the Nold vs. DLB individuals, the following 12 LLC solutions in alpha sources overcome the threshold of 0.7 of the AUROC curve (Table 4): (1) interhemispheric LLC solutions in the parietal alpha 2, temporal alpha 2, parietal alpha 3 , and temporal alpha 3 sources and (2) intrahemispheric LLC solutions in the central alpha 2, parietal alpha 3, temporal alpha 2, occipital alpha 2, central alpha 3, parietal alpha 3, occipital alpha 3, and temporal alpha 3 sources. Among these LLC solutions, the intrahemispheric 2 LLC solutions in the central alpha sources reached the following best classification rate (Figure 7 , bottom): a sensitivity of $83.5 \%$, a specificity of $65 \%$, an accuracy of $74.3 \%$, and 0.78 of the AUROC curve.

\section{Insert here Figure 7 and Table 4}

\section{Control analysis}

As mentioned above, head volume condution and "common drive/source" on EEG signals may mislead estimates (especially "bivariate") of functional connectivity inducing a number of "false" connections between pairs of scalp sensors or source solutions. Typically, these "false" connections are characterized by a "random" spatial topology. Keeping in mind the considerations, we performed a control analysis focused on the alpha souces (a relevant EEG frequency band in the present study) aimed at testing the hypotheses that 1) the present LLC solutions did not show a "random" spatial scheme between the pairs of ROIs in the Nold group and 2) the statistical differences in the alpha LLC solutions between the Nold group and the ADD, PDD or DLB group did not show a "random" spatial scheme between the ROI pairs. To test these hypotheses, we used the following ANOVA designs with LLC solutions between pairs of ROls as a dependent variable. The post-hoc analysis compared 
the LLC solutions for between the pairs of ROIS using a liberal threshold of $p<0.05$ allowing a "random" topology of the functional connections to emerge, if present.

The first control ANOVA design was focused on the alpha LLC solutions of the Nold group ( $p<0.05$ ). The ANOVA factors were Band (alpha 2 and alpha 3 ) and Pair of ROls (frontal-central, frontal-temporal, central-temporal, frontal-parietal, central-parietal, temporal-parietal, frontal-occipital, central-occipital, temporal-occipital, and parietaloccipital). The results showed a significant main effect for the factor Pair of ROls ( $F=35.9, p$ $<0.00001)$, regardless the alpha sub-bands. The Duncan post-hoc analysis showed a characteristic topology of the pairs of ROls exhibiting the greatest effects. For example, the parietal-occipital alpha LLC solutions were higher than those in the temporal-occipital $(p<$ $0.00001)$, temporal-parietal ( $p<0.00005)$, central-parietal $(p<0.00001)$, central-temporal $(p$ $<0.00001)$, frontal-temporal $(p<0.00001)$, and frontal-central $(p<0.00001)$, despite a similar spatial distance between the ROls in those pairs. In the same line, the temporalparietal alpha LLC solutions were higher than those in the frontal-temporal $(p<0.00001)$ and frontal-central $(p<0.00001)$, despite a similar spatial distance between the ROIs in those pairs. The Figure $8(\mathrm{~A})$ and Table 5 report all details of the results of the first control ANOVA design. These results are not in line with a "random" topology of the functional connections.

The second control ANOVA design was focused on the alpha LLC solutions in the comparison between the Nold and the ADD group $(p<0.05)$. The ANOVA factors were Group (Nold and ADD), Band (alpha 2 and alpha 3), and Pair of ROIs (frontal-central, frontaltemporal, central-temporal, frontal-parietal, central-parietal, temporal-parietal, frontaloccipital, central-occipital, temporal-occipital, and parietal-occipital). The results showed a significant Interaction Group X Pair of ROIs ( $F=5.7, p<0.00001)$, regardless the alpha subbands. The Duncan post-hoc analysis showed a characteristic topology of the pairs of ROls having the highest values of alpha LLC solutions in the ADD group. For example, the parietaloccipital alpha LLC solutions were higher than those in the frontal-central $(p<0.00001)$ and central-temporal ( $p<0.0001$ ) pairs of ROIs, despite a similar spatial distance between the ROIs in those pairs. The Duncan post-hoc analysis also showed the pairs of ROls exhibiting the significant differences in the alpha LLC solutions between the Nold and the ADD group. Compared to the Nold group, the ADD group showed lower alpha LLC solutions in frontal- 
temporal, central-temporal, central-parietal, temporal-parietal, central-occipital, temporaloccipital, and parietal-occipital pairs of ROIs ( $p<0.005$ to 0.000001 ). Among them, a clear topology emerged. For example, the differences were higher in the parietal-occipital $(p<$ $0.00001)$ than the temporal-parietal ( $<<0.0005)$, temporo-occipital $(p<0.001)$, frontaltemporal ( $p<0.005)$, and frontal-central (n.s.) pairs of ROls. The Figure 8 (B) report all details of the results of the second control ANOVA design. These results are not in line with a "random" topology of the differences in the functional connections between the Nold and the ADD group.

The third control ANOVA design was focused on the alpha LLC solutions in the comparison between the Nold and the PDD group $(p<0.05)$. The ANOVA factors were Group (Nold and PDD), Band (alpha 2 and alpha 3), and Pair of ROIs (frontal-central, frontaltemporal, central-temporal, frontal-parietal, central-parietal, temporal-parietal, frontaloccipital, central-occipital, temporal-occipital, and parietal-occipital). The results showed a significant Interaction Group X Pair of ROIs ( $F=2.5, p<0.01$ ), regardless the alpha subbands. The Duncan post-hoc analysis showed a characteristic topology of the pairs of ROIs having the highest values of alpha LLC solutions in the PDD group. For example, the parietaloccipital alpha LLC solutions were higher than those in the parietal-temporal $(p<0.01)$ pairs of ROIs, despite a similar spatial distance between the ROIs in those pairs. In the same line, the central-parietal alpha LLC solutions were higher than those in the frontal-central $(p<$ $0.00001)$ and frontal-parietal ( $p<0.00001)$ pairs of ROIs. The Duncan post-hoc analysis also showed a characteristic topology of the pairs of ROIs exhibiting the significant differences in the alpha LLC solutions between the Nold and the PDD group $(p<0.05)$. Compared to the Nold group, the PDD group showed lower alpha LLC solutions only in the central-temporal, central-parietal, temporal-parietal, and parietal-occipital pairs of ROIs ( $p<0.05$ to 0.00001 ). The Figure 8 (C) report all details of the results of the third control ANOVA design. These results are not in line with a "random" topology of the differences in the functional connections between the Nold and the PDD group.

The fourth control ANOVA design was focused on the alpha LLC solutions in the comparison between the Nold and the DLB group $(p<0.05)$. The ANOVA factors were Group (Nold and DLB), Band (alpha 2 and alpha 3), and Pair of ROls (frontal-central, frontaltemporal, central-temporal, frontal-parietal, central-parietal, temporal-parietal, frontal- 
occipital, central-occipital, temporal-occipital, and parietal-occipital). The results showed a significant Interaction Group X Pair of ROIs ( $F=4.2, p<0.00005)$, regardless the alpha subbands. The Duncan post-hoc analysis showed a characteristic topology of the pairs of ROIs having the highest values of alpha LLC solutions in the DLB group. For example, the parietaloccipital alpha LLC solutions were higher than those in the central-temporal $(p<0.001)$, and frontal-central $(p<0.0005)$ pairs of ROls, despite a similar spatial distance between the ROIs in those pairs. The Duncan post-hoc analysis also showed a characteristic topology of the pairs of ROls exhibiting the significant differences in the alpha LLC solutions between the Nold and the DLB group $(p<0.05)$. Compared to the Nold group, the DLB group showed lower alpha LLC solutions in the central-temporal, central-parietal, temporal-parietal, central-occipital, temporal-occipital, and parietal-occipital ( $p<0.005$ to 0.000001 ). Among them, a clear topology emerged. For example, the differences were higher in the parietaloccipital ( $p<0.000001)$ than the temporal-parietal $(p<0.00001)$, temporo-occipital $(p<$ 0.005), frontal-central (n.s.), and frontal-temporal (n.s.) pairs of ROls, despite a similar spatial distance between the ROIs in those pairs. The Figure 8 (D) report all details of the results of the third control ANOVA design. These results are not in line with a "random" topology of the differences in the functional connections between the Nold and the DLB group.

\section{Insert here Figure 8 and Table 5}

\section{Discussion}

In the present exploratory investigation, we re-analyzed the rSEEG data of a previous reference study (Babiloni et al., 2017) to test the core hypothesis that ADD patients might show the maximum abnormality of "functional cortical connectivity" compared with DLB and PDD patients, leading support to the idea of AD as a "cortical disconnection syndrome", Intrahemisphericly and Interhemisphericly (Besthorn et al., 1994; Bokde et al., 2009; Dunkin et al., 1995; Leuchter et al., 1994; Reuter-Lorenz and Mikels, 2005; Teipel et al., 2016). The data re-analysis was performed computing the interhemispheric and intrahemispheric (eLORETA) LLC solutions in cortical sources of rsEEG rhythms at individually-selected frequency bands. The results are summarized and discussed in the following sections. 
The functional cortical connectivity in alpha sources was maximally abnormal in the $A D$ group

In the Nold group as a physiological reference, interhemispheric and intrahemispheric LLC solutions were dominant in posterior alpha sources, suggesting a possible strict relationship of this extensive posterior functional connectivity with the prominent local activation of the same alpha sources, previously reported from the same database (Babiloni et al., 2017). Compared to the Nold group, the decrement of LLC solutions in alpha sources was dramatic in the ADD group, marked in the DLB group, and moderate in the PDD group. Furthermore, he intrahemispheric LLC solutions in widespread alpha sources exhibited a greater reduction in both ADD and DLB groups when compared to the PDD group. Finally, the LLC solutions in frontal alpha sources pointed to a very marked reduction in the ADD group compared with the moderate decrease found in both DLB and PDD groups.

On one hand, these findings might reflect similarities and differences in cortical neuropathology and clinical features among ADD, DLB, and PDD. This similarity was observed between ADD and DLB in a recent retrospective study based on data from 213 patients receiving a diagnosis of LBD and $\alpha$ synucleinopathy confirmed by brain autopsy (Irwin et al., 2017). There were $23 \%$ patients with no AD neuropathology, 26\% with lowlevel AD neuropathology, 21\% with intermediate-level AD neuropathology, and 30\% with high-level AD neuropathology (Irwin et al., 2017). Furthermore, the increased AD neuropathology was associated with higher cerebral $\alpha$-synuclein scores and a shorter interval between the onset of motor or dementia symptoms and the death (Irwin et al., 2017). In another study, about $25 \%$ of DLB patients and $9 \%$ of PDD patients had abnormal CSF values for t-tau, $A \beta 42$, and $p$-tau, thus suggesting that a CSF profile of $A D$ is more common in DLB compared with PDD patients (van Steenoven et al., 2016). Moreover, there was evidence that compared with DLB patients with AD neuropathology, DLB patients without AD neuropathology showed greater impairment on visuospatial constructions, visual conceptual reasoning, the speed of processing, and more frequent hallucinations, but less impairment of confrontation naming and verbal memory (Peavy et al., 2016). Finally, compared with DLB patients negative to pathophysiological $A \beta 42$ and 
tau markers in CSF, DLB patients positive to those markers showed a greater decline in the MMSE score (Abdelnour et al., 2016).

The present evidence of a common frontal effect in the DLB and PDD groups might be explained by the partially common neuropathology of subcortical projection to the frontal lobe and similar clinical features in the two diseases (Barker and Williams-Gray, 2016). Both neurodegenerative dementing disorders share characteristic neuropathological changes including deposition of $\alpha$-synuclein in Lewy bodies and neurites, loss of tegmental dopamine cell populations, loss of basal forebrain cholinergic projection to the cortex, and a variable degree of coexisting AD neuropathology (Irwin et al., 2017). Clinical constellations of both DLB and PDD include progressive cognitive impairment associated with parkinsonism, visual hallucinations, frontal executive dysfunctions, and fluctuations of attention and wakefulness (Barker and Williams-Gray, 2016).

The present results extend to source space and individually-determined frequency bands previous EEG evidence showing differences in the functional cortical connectivity estimated from scalp rsEEG rhythms in ADD, PDD, and DLB groups compared with Nold subjects (Adler et al., 2003; Andersson et al., 2008; Anghinah et al., 2000; Besthorn et al., 1994; Dunkin et al., 1994; Fonseca et al., 2011, 2013; Jelic et al., 1997, 2000; Knott et al., 2000; Leuchter et al., 1987, 1992; Locatelli et al., 1998; Moazami-Goudarzi et al., 2008; Pogarell et al., 2005; Sloan et al., 1994; van Dellen et al., 2015). In previous studies, ADD patients were characterized by lower functional cortical connectivity computed from posterior alpha $(8-12 \mathrm{~Hz})$ and beta $(13-20 \mathrm{~Hz})$ rhythms but the topographical regional localization of the effects was not consistent across the investigations with the exception of a prominent anterior-posterior axis of the connectivity alteration (Adler et al., 2003; Anghinah et al., 2000; Babiloni et al., 2004, 2006b, 2016b; Besthorn et al., 1994; Blinowska et al., 2017; Dunkin et al., 1994; Fonseca et al., 2011, 2013; Jelic et al., 1997, 2000; Knott et al., 2000; Leuchter et al., 1987, 1992; Locatelli et al., 1998; Pogarell et al., 2005; Sloan et al., 1994). Similarly, the present results extend as spatial and frequency specifications the previous evidence of abnormalities of the interhemispheric and intrahemispheric scalp frontoparietal alpha coherences in PD patients with cognitive 
deficits (Fonseca et al., 2013; Teramoto et al., 2016) and DLB subjects (Dauwan et al., 2016a).

Previous investigations in animals have delineated an interesting model of the generation of cortical alpha rhythms in quiet wakefulness (Hughes \& Crunelli, 2005; Lörincz et al., 2008, 2009). These rhythms might result from a physiological neurotransmission between populations of cortical pyramidal, thalamocortical, and reticular thalamic neurons (Hughes \& Crunelli, 2005; Lörincz et al., 2008, 2009). Alpha rhythms in that thalamocortical network may produce cycles of neuronal excitation and inhibition that might frame perceptual events in discrete snapshots of around $70-100 \mathrm{~ms}$ during active sensory and motor information processing (Hughes \& Crunelli, 2005; Lörincz et al., 2008, 2009). In this line, the present evidence of reduced alpha source connectivity in patients with dementia -especially in ADD subjects- might be due to a downregulation of that neurophysiological mechanism. As a result, an unselective tonic cortical excitation might occur in quiet wakefulness. Such cortical over excitation could represent a sort of background noise, possibly interfering with the switch of the cerebral cortex from quiet wakefulness to focused attention and local adaptive encoding and retrieval information processing when required by endogenous or external demands (Babiloni et al., 2016a).

The functional cortical connectivity in delta sources was abnormal only in the AD group

Here we report the negligible magnitude of the interhemispheric and intrahemispheric LLC solutions in delta sources estimated in the Nold group and the abnormal increase only in the ADD group. Specifically, the interhemispheric LLC solutions in the occipital delta sources were higher in the ADD than the Nold and PDD groups. Furthermore, the intrahemispheric LLC solutions in distributed delta sources were greater in the ADD than the Nold group, while those LLC solutions in temporal delta sources were higher in the ADD than the Nold, PDD, and DLB groups.

The fact that delta source connectivity was abnormal in the ADD group but not the DLB and PDD groups was surprising as the delta sources of rsEEG rhythms were more abnormal in the same DLB and PDD patients compared with the AD ones in our previous reference study (Babiloni et al., 2017). We discussed this surprising dissociation of delta 
source "synchronization/desynchronization" and "functional cortical connectivity" in a subsequent paragraph.

The present findings agree with a previous study comparing LLC solutions in delta sources between Nold and ADD individuals (Babiloni et al., 2016a). Furthermore, they enrich with spatial details and individual frequency bands previous evidence showing differences in functional connectivity measurements from delta rhythms at scalp sensors between Nold and ADD individuals (Adler et al., 2003; Blinowska et al., 2017; Knott et al., 2000; Locatelli et al., 1998; Sankari et al., 2011;).

The present evidence of normal delta LLC solutions in DLB and PDD patients contrasts previous findings showing lower (Andersson et al., 2008; van Dellen et al., 2015) or higher (Kai et al., 2005; van Dellen et al., 2015) delta connectivity in DLB compared with ADD patients. At the present early stage of the research, we cannot give a final explanation for these discrepancies. It is unclear if they depend on (1) the current technique of multivariate LLC rather than bivariate coherence for the estimation of the rsEEG functional interdependence, (2) the computation of the functional connectivity at the cortical source rather than the scalp sensor level (e.g. LLC solutions in the source space and spectral coherence computed between scalp electrode pairs may be differently affected by residual ocular or muscular artifacts in the EEG signals), and (3) the use of individual rather than fixed frequency bands for the analysis of delta rhythms. Future studies should vary the mentioned methodological options systematically in the same database to clarify the matter.

The neurophysiological mechanism generating human delta rhythms in quiet wakefulness is poorly known. A speculative explanation is that normal delta rhythms in quiet wakefulness are generated by intrinsic thalamocortical interactions associated with a relative functional isolation of cortical modules from the sensory flow, analogously to the neurophysiological mechanism producing slow waves in non-REM sleep (Crunelli et al., 2015). Another speculative explanation is that the generating mechanism might be the "stand-by" mode of selective circuits of corticothalamic and relay thalamocortical neurons engaged in a fast information processing during cognitive tasks (Taylor et al., 2014).

In the above theoretical framework, it can be just speculated that the present evidence of an abnormal posterior delta source connectivity in the ADD patients might 
reflect an abnormal upregulation of the mechanisms generating normal delta rhythms in quiet wakefulness. In ADD patients, that upregulation might result from cortical blood hypoperfusion and synaptic dysfunction in the same regions (Niedermeyer et al., 1997; Passero et al., 1995; Rodriguez et al., 1999; Valladares-Neto et al., 1995). Other causes might be a white matter lesion (Agosta et al., 2013, 2014) or the loss of neurons in the cortical gray matter, especially in the posterior cortex (Babiloni et al., 2013, 2015b; Delli Pizzi et al., 2014, 2015, 2016; Fernandez et al., 2003; Graff-Radford et al., 2016; Sarro et al., 2016).

The LLC solutions in delta and alpha sources classified Nold vs. patients with dementia

Here we report the results of two exploratory analyses aimed at testing the clinically relevance of the present findings. The first analysis showed significant positive correlations between MMSE scores (roughly reflecting global cognitive status) and LLC solutions in interhemispheric temporal and intrahemispheric diffuse alpha sources across all Nold, ADD, DLB, and PDD individuals as a whole group. However, even if statistically significant $(p<0.005)$, the correlation values were relatively low as variance explained (i.e. $r=0.24-0.26)$. Furthermore, no statistically significant correlation $(p>0.05)$ was observed for any single group considered separately. The present findings suggest that neurophysiological mechanisms of the interdependence of cortical neural synchronization/desynchronization underpinning brain arousal and low vigilance (as reflected in the LLC solutions of this study) are only one of the determinants of global cognitive functions in human subjects. Other relevant neurophysiological mechanisms involved in cognitive information processes may be those related to selective attention, encoding and retrieval of information in long-term memory, frontal executive functions (some assisted by internal language), and others. Therefore, future studies may measure functional connectivity not only during the resting state condition (i.e. low vigilance) but also during attention, episodic and working memory, and other cognitive tasks. The derived EEG markers may be used as a multivariate input for linear (logistics regression) and non-linear (artificial neural networks or support vector machines) predictors of the MMSE score in Nold subjects and patients with dementing disorders. The expected results 
may show high correlation values and remarkable insights about the derangement of brain functions in the evolution of dementing disorders.

The second analysis pointed to a moderate classification accuracy of several alpha LLC solutions in the discrimination of ADD vs. Nold, DLB, and PPD individuals. Specifically, interhemispheric LLC solutions in the temporal alpha sources showed an AUROC curve of 0.84 vs. Nold individuals and 0.75 vs. DLB individuals while intrahemispheric LLC solutions in the central alpha sources exhibited an AUROC curve of 0.78 vs. PDD individuals. Noteworthy, the only substantial classification accuracy of the LLC solutions in delta sources was obtained with the interhemispheric LLC solutions in occipital delta sources discriminating Nold subjects vs. ADD patients (e.g. AUROC curve of 0.7).

The present findings are in line with previous evidence showing the following values of classification accuracy (1) 1.0-0.45 for Nold vs. ADD individuals (e.g. $1=100 \%$ ); (2) $0.92-0.78$ for $\mathrm{MCl}$ vs. ADD individuals; and (3) $0.87-0.60$ for the conversion from $\mathrm{MCl}$ to ADD status (Adler et al., 2003; Babiloni et al., 2015b, 2016b; Bennys et al., 2001; Blinowska et al., 2017; Brassen et al., 2004; Buscema et al., 2007; Claus et al., 1999; Engedal et al., 2015; Garn et al., 2017; Huang et al., 2000; Jelic et al., 2000; Knyazeva et al., 2010; Lehmann et al., 2007; Lizio et al., 2016; Missonnier et al., 2006; Nuwer, 1997).

Concerning the classification of Nold vs. DLB and PDD individuals, the present discrimination with $0.75-0.78$ of success was intermediate when compared with those reported in previous studies. In those investigations, global delta and alpha coherences between electrode pairs allowed a classification accuracy of $0.75-0.80$ of DLB individuals compared with Nold subjects (Andersson et al., 2008). Another study (Roks et al., 2008) used grand total EEG score to discriminate DLB vs. Nold individuals with an accuracy of 0.78. Finally, two advanced procedures using a combination of 20-25 discriminant rsEEG power density and connectivity measurements showed a classification accuracy of 0.80 1.0 between PDD/DLB and Nold individuals (Engedal et al., 2015; Garn et al., 2017; Snaedal et al., 2012). Noteworthy, no previous cross-validated comparisons showed the ability of rSEEG markers in the discrimination of PDD vs. DLB patients to delineate the bounds between these entities at the individual level.

The clinical neurophysiological model 
In the reference study carried out in the same populations of the present investigation (Babiloni et al., 2017), rSEEG markers of "synchronization/desynchronization" were investigated. Results of that previous study suggest that posterior alpha source synchronization reduced dramatically in the ADD group, markedly in the DLB group, and moderately in the PDD group. In contrast, posterior delta source synchronization increased dramatically in the PDD group, markedly in the DLB group, and moderately in the ADD group. Compared to those findings, the present markers of "functional cortical connectivity" suggest maximum abnormalities of both delta and alpha source connectivity in the ADD group compared to the DLB and PDD groups, thus confirming the working hypothesis of this study. Interestingly, the present markers of "functional cortical connectivity" also suggest more abnormalities of alpha source connectivity in the DLB group compared to the PDD group.

Keeping in mind these findings, two main considerations can be done. The first consideration is that the markers of the neurophysiological reserve lead support to the concept of ADD as "cortical disconnection syndrome." The second consideration is that the combination of the markers of "synchronization/desynchronization" and "functional cortical connectivity" might enrich the assessment of cholinergic and dopaminergic neurotransmission in ADD, DLB, and PDD.

Based on the present results and those of Babiloni and colleagues (2017), the distinguishing markers of the neurophysiological reserve in ADD patients might be a dramatic decrease of both "synchronization/desynchronization" and "functional cortical connectivity" in posterior alpha sources. Furthermore, these patients might show an increase of both those markers in posterior delta sources.

In contrast, the distinguishing markers of the neurophysiological reserve in PDD and DLB patients might be a dissociation of "synchronization/desynchronization" and "functional cortical connectivity" markers in posterior delta sources, namely a marked increase of the former without a related increase of the latter.

In this framework, ADD patients exhibited more similarities to DLB than PDD patients for both markers of "synchronization" and "functional cortical connectivity" in alpha and delta sources. 
An exciting hypothesis for future studies is that those markers of the neurophysiological reserve might reflect cholinergic dysfunction in the $A D D$, cholinergic and dopaminergic dysfunction in DLB, and dopaminergic dysfunction in the PDD. Those studies should correlate the hypothesized rSEEG markers of cholinergic and/or dopaminergic dysfunction and relevant PET readouts of dopaminergic and cholinergic uptake in the brain. More questionable may be the acute use of scopolamine and risperidone in $A D D, D L B$, and PDD patients for the risk of clinical side effects. Overall, the evaluation of that clinical neurophysiological model is motivated by some encouraging previous evidence reported in the following paragraphs.

Previous studies have unveiled a relationship between resting state delta and alpha rhythms and cholinergic neurotransmission in ADD patients. Indeed, it has been shown that AChEI drugs (i.e. enhancing the cholinergic tone) exerted beneficial effects on some rsEEG frequency bands, namely decreasing delta (Adler and Brassen, 2001; Balkan et al., 2003; Gianotti et al., 2008; Reeves et al., 2002) and theta (Adler et al., 2004; Brassen and Adler, 2003; Gianotti et al., 2008) while increased alpha power density (Agnoli et al., 1983; Babiloni et al., 2006c; Balkan et al., 2003).

In healthy subjects, an acute dose of scopolamine (i.e. a muscarinic cholinergic antagonist) compared with placebo transiently increased delta and theta power density while reduced alpha and beta power density, in the way typically found in ADD patients (Ebert and Kirch, 1998). In addition, the scopolamine increased delta and reduced alpha power density in relation to plasma drug concentration and transient psychomotor impairment (Liem-Moolenaar et al., 2011a).

In both Nold and ADD patients, the acute scopolamine intervention induced decreased alpha power density and increased delta power density, the drop in the Nold subjects being stronger as expected by the integrity of their cholinergic neurotransmission (Neufeld et al., 1994). More recently, an acute dose of scopolamine produced deranging effects on composite measurements of power density and coherence of delta, theta, alpha, beta, and gamma that had been successfully used to classify Nold and ADD individuals (Johannsson et al., 2015; Snaedal et al., 2010).

Unfortunately, less clear is the relationship between the mentioned rsEEG markers in delta sources and dopaminergic neurotransmission in PDD and DLB patients. Some 
previous studies provided support to the hypothesized relationship. Compared with Nold subjects, PD patients showed higher delta and theta power density in several scalp regions, more evident in association with a progressive cognitive impairment (Bonanni et al., 2008; Caviness et al., 2007; Morita et al., 2009, 2011; Pugnetti et al., 2010). Furthermore, these features appeared to be specific, as delta and theta power density values were higher in PDD patients than in ADD, PD, and Nold subjects (Babiloni et al. 2011; Fonseca et al., 2013). Moreover, these features were specifically related to phosphorylation of $\alpha$-synuclein in the posterior cingulate cortex (hub of the default mode network), namely the higher the $\alpha$-synuclein load, the higher the global delta, the lower the global alpha power density, and the lower the frequency alpha peak (Caviness et al., 2016).

In the same line, global delta and theta power density and variability were higher in DLB than ADD patients (Andersson et al., 2008; Kai et al., 2005). The global delta power density fluctuated more in DLB than ADD patients within 1 hour of rsEEG recording (Andersson et al. 2008; Walker et al., 2000a, b).

In healthy subjects, an acute dose of risperidone (i.e. an atypical antipsychotic dopamine and serotoninergic antagonist) compared with placebo transiently increased delta and/or theta power density of rSEEG rhythms in relation to plasma drug concentration (Lee et al., 1999) and transient psychomotor impairment (Hughes et al., 1999; Liem-Moolenaar et al., 2011b).

Noteworthy, other studies challenge the specificity of the relationship between the mentioned rsEEG markers in delta sources and dopaminergic neurotransmission in PDD and DLB patients. It was reported that treatment with AChEI (i.e. donepezil) partially normalized delta and theta power density (but not alpha) in DLB patients, while there was no significant difference in ADD patients. (Kai et al., 2005). Furthermore, L-DOPA and electrical stimulation of subthalamic nucleus enhancing the dopaminergic tone reduced intrahemispheric frontoparietal alpha and beta (but not delta) coherences in association with an improvement of motor symptoms in PD patients (Moazami-Goudarzi et al., 2008; Silberstein et al., 2005). Also, intrahemispheric fronto-temporo-central delta and theta coherences were higher in DLB than in ADD patients (Andersson et al., 2008). Finally, global alpha coherence over the whole scalp was lower in DLB than ADD patients while 
global delta coherence was higher in the former than in the latter group (Andersson et al., 2008).

These mixed results in the literature confirms the complexity of the interactions and confounds related to comorbidities (e.g. depression, behavioral symptoms), psychoactive drugs, different stages of the diseases, and different levels of the impairment in cholinergic and dopaminergic systems in ADD, DLB, and PDD patients. A possible design to disentangle these variables may be a longitudinal study in de-novo $A D D$, DLB, and PDD patients, free from major depression, to be undergone to rsEEG recordings before and after chronic administration of cholinergic and dopaminergic therapy. In these patients, levels of the impairment in cholinergic and dopaminergic systems may be measured by PET using radio ligands for cholinergic markers and DATSCAN, respectively. Of note, those radio ligands for cholinergic markers such as $\left[{ }^{11} \mathrm{C}\right] \mathrm{MP} 4 \mathrm{~A}$ and $\left[{ }^{11} \mathrm{C}\right] \mathrm{PMP}$ PET for acetylcholinesterase (AChE), $\left[{ }^{123} \mid\right] 5 \mathrm{IA}$ SPECT for the $\alpha_{4} \beta_{2}$ nicotinic acetylcholine receptor and [123I]IBVM SPECT for the vesicular acetylcholine transporter have shown that cortical AChE was reduced in PDD and ADD patients in relation with the level of performance in attention and working memory tests (see a review in Roy et al., 2016).

\section{Methodological remarks}

In the reference study carried out in the same populations (Babiloni et al., 2017), we discussed some methodological limitations of this retrospective and explorative study. Summarizing, these limitations include the relatively small number of the patients $(N=$ 34-42) and the lack of (1) unified experimental recording protocol, (2) harmonized hardware for EEG recordings and neuroimaging, (3) extensive neuroimaging (e.g. DATSCAN), (4) neuropsychological battery (e.g. ADAS-Cog) in all clinical Units (e.g. the MMSE score may be not equally sensitive to global cognitive deficits in all neurodegenerative dementing disorders), (5) groups of patients with prodromal stages of the disease (i.e. no anti-dementia pharmacological therapy), and (6) repeated recordings over time.

Here two additional methodological limitations are discussed. In the present study, $128 \mathrm{~Hz}$ sampling rate was used for the data analysis as a frequency available in all 
clinical units of this international Consortium. Noteworthy, this sampling rate is not optimal for the analysis of gamma band, especially for frequencies higher than $40 \mathrm{~Hz}$. An optimal setting of EEG recording parameters may use 256 or $512 \mathrm{~Hz}$ to cover the whole gamma rage and high-frequency oscillations $>40 \mathrm{~Hz}$. However, the use of $128 \mathrm{~Hz}$ sampling rate did not affect the main findings of the present study found at delta and alpha frequency bands, ranging $<13 \mathrm{~Hz}$. Furthermore, the Figures 2 and 3 of this article showed that the LLC solutions at beta 2 and gamma $(20-40 \mathrm{~Hz})$ bands were negligible in the present experimental conditions (i.e. eyes closed resting state). Therefore, it is not probable that relevant effects may be observed at higher frequencies in these conditions.

In this study, another specific methodological limitation should be remarked. We used the toolbox LLC of eLORETA freeware (Pascual-Marqui et al., 2011) to estimate the functional connectivity between rsEEG cortical sources in Nold, ADD, PDD, and DLB groups of subjects. Specifically, LLC estimates and removes zero-lag phase source interactions from the total linear connectivity in pairs of EEG cortical sources to mitigate at least in part the effects of head volume conduction (Pascual-Marqui et al., 2011). As a bivariate measurement of lagged interactions between two cortical sources, LLC may not remove the "common drive" effect of a third brain source sending action potentials to that pair of sources examined. This effect may cause a number of "false" connections between pairs of scalp sensors or source solutions in the readouts of the procedures (especially bivariate) used for estimation of EEG functional connectivity. Typically, those "false" connections are characterized by a "random" spatial topology. For this reason, we performed 4 control analyses to test the hypotheses that the present LLC solutions did not show a "random" spatial scheme between the pairs of ROls in the Nold and the dementia groups. As an example, we used the LLC solutions computed for alpha rhythms. Results of these control analyses were not in line with a "random" topology of the pattern of functional EEG source connectivity of alpha rhythms (as reference dominant rsEEG rhythms) in the Nold group. In the same vein, they did not show a "random" topology of the pattern of the differences in functional EEG source connectivity of alpha rhythms between the Nold and the dementia groups. However, the present results did not exclude that part of the shown effects were due to common drive phenomenon. Therefore, future investigations will have to address this issue on simulated and real data, allowing a better 
understanding of the reliability and validity of the LCC estimates of rsEEG source connectitivty with reference to head volume condution and common drive/source effects. In this line, other EEG functional connectivity metrics, which are related to Granger causality, may be helpful to exclude the spurious lagged connectivity due to head volume condution and common drive effects. These are the directed transfer function (DTF; Kamiński and Blinowska, 1991) and the partial directed coherence (PDC; Baccalá and Sameshima, 2001). In the original implementations, both procedures are grounded on phase differences between EEG signals recorded at scalp electrodes. Among them, DTF shows not only direct, but also cascade flows, namely in case of propagation when there is a phase difference between signals (Blinowska, 2011). Another interesting procedure is the computation of "isolated effective coherence", estimating the partial coherence in the eLORETA source space under a multivariate autoregressive model (Pasqual-Marqui et al., 2014).

\section{Conclusions}

Previous evidence showed abnormal markers of cortical neural "synchronization/desynchronization" in quiet wakefulness in ADD, DLB, and PDD patients, as revealed by posterior sources of delta $(<4 \mathrm{~Hz})$ and alpha $(8-12 \mathrm{~Hz})$ rhythms (Babiloni et al., 2017). We proposed that those markers might probe the neurophysiological reserve in those patients. The present exploratory study tested the hypothesis that another class of markers might probe the patients' neurophysiological reserve, namely the markers of "functional cortical connectivity." These markers might be especially informative in AD individuals, supposed to suffer from a "disconnection cortical syndrome" (Bokde et al., 2009; Teipel et al., 2016).

At the group level, the present results indicated that interhemispheric and intrahemispheric LLC solutions in widespread delta sources were abnormally higher in the ADD group and, surprisingly, normal in the DLB and PDD groups. Intrahemispheric LLC solutions were reduced in widespread alpha sources dramatically in the ADD group, markedly in the DLB group, and moderately in the PDD group. Furthermore, the interhemispheric LLC solutions showed lower values in the ADD and DLB groups than the PDD group. 
At the individual level, AUROC curves of LLC solutions in alpha sources exhibited better classification accuracies for the discrimination of ADD vs. Nold individuals (0.84) than for Nold vs. DLB (0.78) and Nold vs. PDD alpha (0.75).

These findings suggest that functional cortical connectivity in both delta and alpha sources might unveil more compromised neurophysiological reserve in Alzheimer's than Lewy bodies' dementia, at both group and individual levels. This effect might occur Interhemisphericly and Intrahemisphericly, with more discrimination between the ADD and DLB groups Interhemisphericly.

These findings motivate future prospective, multi-center studies using a detailed evaluation of the patients' cognitive status, harmonized EEG hardware systems, and unique data collection protocols. Those future studies will aim to cross-validate the present results and improve our understanding of the effects of neurodegenerative dementing disorders on the rsEEG markers of the neurophysiological reserve, namely those of "synchronization/desynchronization" and "functional cortical connectivity." An exciting hypothesis for those studies is that the combination of "synchronization/desynchronization" and "functional cortical connectivity" markers might be valid topographic biomarkers of $A D D, D L B$, and PDD for clinical applications and research (i.e. the stratification of patients based on an index of neurophysiological reserve and the evaluation over time of the mechanistic effect of interventions). 


\section{References}

Aarsland D, Litvan I, Salmon D, Galasko D, Wentzel-Larsen T, Larsen JP. Performance on the dementia rating scale in Parkinson's disease with dementia and dementia with Lewy bodies: comparison with progressive supranuclear palsy and Alzheimer's disease. J Neurol Neurosurg Psychiatry 2003;74:1215-20.

Abdelnour C, van Steenoven I, Londos E, Blanc F, Auestad B, Kramberger MG, Zetterberg $H$, Mollenhauer B, Boada M, Aarsland D; European DLB Consortium. Alzheimer's disease cerebrospinal fluid biomarkers predict cognitive decline in lewy body dementia. Mov Disord. 2016 Aug;31(8):1203-8.

Adler G, Brassen S. Short-term rivastigmine treatment reduces EEG slow-wave power in Alzheimer patients. Neuropsychobiology. 2001;43(4):273-6.

Adler G., Brassen S., Jajcevic J.. EEG coherence in Alzheimer's dementia. J Neural Transm, 110 (2003), pp. 1051-1058.

Adler G, Brassen S, Chwalek K, Dieter B, Teufel M. Prediction of treatment response to rivastigmine in Alzheimer's dementia. J Neurol Neurosurg Psychiatry. 2004 Feb;75(2):2924.

Agnoli A, Martucci N, Manna V, Conti L, Fioravanti M. Effect of cholinergic and anticholinergic drugs on short-term memory in Alzheimer's dementia: a neuropsychological and computerized electroencephalographic study. Clin Neuropharmacol. 1983;6(4):311-23.

Agosta F, Canu E, Stojković T, Pievani M, Tomić A, Sarro L, Dragašević N, Copetti M, Comi G, Kostić VS, Filippi M. The topography of brain damage at different stages of Parkinson's disease. Hum Brain Mapp. 2013;34:2798-807.

Agosta F, Canu E, Stefanova E, Sarro L, Tomić A, Špica V, Comi G, Kostić VS, Filippi M. Mild cognitive impairment in Parkinson's disease is associated with a distributed pattern of brain white matter damage. Hum Brain Mapp. 2014;35:1921-9.

Albert MS, DeKosky ST, Dickson D, Dubois B, Feldman HH, Fox NC, Gamst A, Holtzman DM, Jagust WJ, Petersen RC, Snyder PJ, Carrillo MC, ThiesB, Phelps CH. The diagnosis of mild cognitive impairment due to Alzheimer's disease: recommendations from the National Institute on Aging-Alzheimer's Association workgroups on diagnostic guidelines for Alzheimer's disease. Alzheimers Dement 2011; 7:270-279.

American academy of sleep medicine. The International Classification of Sleep disorders. Diagnostic and coding manual. 1992

American Academy of Sleep Medicine, 2014. International Classification of Sleep Disorders, third ed. American Academy of Sleep Medicine, Darien, IL.

American Psychiatric Association. Diagnostic and statistical manual of mental disorders (4th ed., rev) 2000; Washington DC.

Andersson M, Hansson O, Minthon L, Rosén I, Londos E. Electroencephalogram variability in dementia with lewy bodies, Alzheimer's disease and controls. Dement Geriatr Cogn Disord. 2008;26:284-90. 
Anghinah R, Kanda PA, Jorge MS, Lima EE, Pascuzzi L, Melo AC. Alpha band coherence analysis of EEG in healthy adult's and Alzheimer's type dementia patients. Arq Neuropsiquiatr. 2000 Jun;58(2A):272-5.

Anonymous. Clinical and neuropathological criteria for fontotemporal dementia. The Lund and Manchester Groups. J Neurol Neurosurg Psychiatry 1994; 57:416-18.

Babiloni C, Ferri R, Moretti DV, Strambi A, Binetti G, Dal Forno G, Ferreri F, Lanuzza B, Bonato C, Nobili F, Rodriguez G, Salinari S, Passero S, Rocchi R, Stam CJ, Rossini PM. Abnormal fronto-parietal coupling of brain rhythms in mild Alzheimer's disease: a multicentric EEG study. Eur J Neurosci. 2004 May;19(9):2583-90.

Babiloni C, Binetti G, Cassetta E, Dal Forno G, Del Percio C, Ferreri F, Ferri R, Frisoni G, Hirata K, Lanuzza B, Miniussi C, Moretti DV, Nobili F, Rodriguez G, Romani GL, Salinari S, Rossini PM. Sources of cortical rhythms change as a function of cognitive impairment in pathological aging: a multi-centric study. Clin Neurophysiol 2006a;117:252-68.

Babiloni C, Ferri R, Binetti G, Cassarino A, Dal Forno G, Ercolani M, Ferreri F, Frisoni GB, Lanuzza B, Miniussi C, Nobili F, Rodriguez G, Rundo F, Stam CJ, Musha T, Vecchio F, Rossini PM. Fronto-parietal coupling of brain rhythms in mild cognitive impairment: a multicentric EEG study. Brain Res Bull. 2006b Mar 15;69(1):63-73.

Babiloni C, Cassetta E, Dal Forno G, Del Percio C, Ferreri F, Ferri R, Lanuzza B, Miniussi C, Moretti DV, Nobili F, Pascual-Marqui RD, Rodriguez G, Luca Romani G, Salinari S, Zanetti $\mathrm{O}$, Rossini PM. Donepezil effects on sources of cortical rhythms in mild Alzheimer's disease: Responders vs. Non-Responders. Neuroimage. 2006c Jul 15;31(4):1650-65.

Babiloni C, Frisoni GB, Vecchio F, Pievani M, Geroldi C, De Carli C, et al. Global functional coupling of resting EEG rhythms is related to white-matter lesions along the cholinergic tracts in subjects with amnesic mild cognitive impairment. J Alzheimer's Dis. 2010;19(3):859-871.

Babiloni C, Carducci F, Lizio R, Vecchio F, Baglieri A, Bernardini S, Cavedo E, Bozzao A, Buttinelli C, Esposito F, Giubilei F, Guizzaro A, Marino S, Montella P, Quattrocchi CC, Redolfi A, Soricelli A, Tedeschi G, Ferri R, Rossi-Fedele G, Ursini F, Scrascia F, Vernieri F, Pedersen TJ, Hardemark HG, Rossini PM, Frisoni GB. Resting state cortical electroencephalographic rhythms are related to gray matter volume in subjects with mild cognitive impairment and Alzheimer's disease. Hum. Brain Mapp. 2013; 34:1427-46.

Babiloni C, Lizio R, Marzano N, Capotosto P, Soricelli A, Triggiani Al, Cordone S, Gesualdo $L$, Del Percio C. Brain neural synchronization and functional coupling in Alzheimer's disease as revealed by resting state EEG rhythms. Int. J. Psychophysiol, 2015a; 103:88102.

Babiloni C, Del Percio C, Boccardi M, Lizio R, Lopez S, Carducci F, Marzano N, Soricelli A, Ferri R, Triggiani Al, Prestia A, Salinari $S$, Rasser PE, Basar E, Famà F, Nobili $F$, Yener $G$, Emek-Savaş DD, Gesualdo L, Mundi C, Thompson PM, Rossini PM, Frisoni GB. Occipital sources of resting-state alpha rhythms are related to local gray matter density in subjects with amnesic mild cognitive impairment and Alzheimer's disease. Neurobiol Aging. 2015b Feb;36(2):556-70. 
Babiloni C, Lizio R, Marzano N, Capotosto P, Soricelli A, Triggiani Al, Cordone S, Gesualdo L, Del Percio C. Brain neural synchronization and functional coupling in Alzheimer's disease as revealed by resting state EEG rhythms. Int J Psychophysiol. 2016a May;103:88102.

Babiloni C, Triggiani Al, Lizio R, Cordone S, Tattoli G, Bevilacqua V, Soricelli A, Ferri R, Nobili F, Gesualdo L, Millán-Calenti JC, Buján A, Tortelli R, Cardinali V, Barulli MR, Giannini A, Spagnolo P, Armenise S, Buenza G, Scianatico G, Logroscino G, Frisoni GB, Del Percio C. Classification of Single Normal and Alzheimer's Disease Individuals from Cortical Sources of Resting State EEG Rhythms. Front Neurosci. 2016b Feb 23;10:47.

Babiloni C, Del Percio C, Lizio R, Noce G, Cordone S, Lopez S, Soricelli A, Ferri R, Pascarelli MT, Nobili F, Arnaldi D, Aarsland D, Orzi F, Buttinelli C, Giubilei F, Onofrj M, Stocchi F, Stirpe P, Fuhr P, Gschwandtner U, Ransmayr G, Caravias G, Garn H, Sorpresi F, Pievani M, Frisoni GB, D'Antonio F, De Lena C, Güntekin B, Hanoğlu L, Başar E, Yener G, Emek-Savaş $\mathrm{DD}$, Triggiani Al, Franciotti R, De Pandis MF, Bonanni L. Abnormalities of cortical neural synchronization mechanisms in patients with dementia due to Alzheimer's and Lewy body diseases: an EEG study. Neurobiol Aging. 2017 Jul;55:143-158.

Baccalá LA, Sameshima K. Partial directed coherence: a new concept in neural structure determination.Biol Cybern. 2001 Jun;84(6):463-74.

Balkan S, Yaraş N, Mihçi E, Dora B, Ağar A, Yargiçoğlu P. Effect of donepezil on EEG spectral analysis in Alzheimer's disease. Acta Neurol Belg. 2003 Sep;103(3):164-9.

Ballard C, Grace J, McKeith I, Holmes C. Neuroleptic sensitivity in dementia with Lewy bodies and Alzheimer's disease. Lancet. 1998 Apr 4;351(9108):1032-3.

Barker RA, Williams-Gray $\mathrm{CH}$. Review: The spectrum of clinical features seen with alpha synuclein pathology. Neuropathol Appl Neurobiol. 2016 Feb;42(1):6-19.

Bennys K, Rondouin G, Vergnes C, Touchon J. (2001) Diagnostic value of quantitative EEG in Alzheimer disease. Neurophysiol. Clin.; 31, 153-160.

Besthorn C, Förstl H, Geiger-Kabisch C, Sattel H, Gasser T, Schreiter-Gasser U. EEG coherence in Alzheimer disease. Electroencephalogr Clin Neurophysiol. 1994 Mar;90(3):242-5.

Bhat S, Acharya UR, Dadmehr N, Adeli H. Clinical Neurophysiological and Automated EEGBased Diagnosis of the Alzheimer's Disease. Eur Neurol. 2015;74:202-10.

Blinowska KJ. Review of the methods of determination of directed connectivity from multichannel data. Med Biol Eng Comput. 2011 May;49(5):521-9.

Blinowska KJ, Rakowski F, Kaminski M, De Vico Fallani F, Del Percio C, Lizio R, Babiloni C. Functional and effective brain connectivity for discrimination between Alzheimer's patients and healthy individuals: A study on resting state EEG rhythms. Clin Neurophysiol. 2017 Apr;128(4):667-680.

Bokde AL, Ewers M, Hampel H. Assessing neuronal networks: understanding Alzheimer's disease. Prog Neurobiol. 2009 Oct;89(2):125-33. 
Bonanni L, Thomas A, Tiraboschi P, Perfetti B, Varanese S, Onofrj M. EEG comparisons in early Alzheimer's disease, dementia with Lewy bodies and Parkinson's disease with dementia patients with a 2-year follow-up. Brain 2008;131(Pt 3):690-705.

Bonanni L, Perfetti B, Bifolchetti S, Taylor JP, Franciotti R, Parnetti L, Thomas A, Onofrj M. Quantitative electroencephalogram utility in predicting conversion of mild cognitive impairment to dementia with Lewy bodies. Neurobiol Aging. 2015;36:434-45.

Bonanni L, Franciotti R, Nobili F, Kramberger MG, Taylor JP, Garcia-Ptacek S, Falasca NW, Famá F, Cromarty R, Onofrj M, Aarsland D; E-DLB study group. EEG Markers of Dementia with Lewy Bodies: A Multicenter Cohort Study. J Alzheimers Dis. 2016 Sep 2.

Bosboom JL, Stoffers D, Stam CJ, van Dijk BW, Verbunt J, Berendse HW, Wolters ECh. Resting state oscillatory brain dynamics in Parkinson's disease: an MEG study. Clin Neurophysiol 2006;117:2521-31.

Bosboom JL, Stoffers D, Wolters ECh, Stam CJ, Berendse HW. MEG resting state functional connectivity in Parkinson's disease related dementia. J Neural Transm 2009;116:193-202.

Brassen S, Adler G. Short-term effects of acetylcholinesterase inhibitor treatment on EEG and memory performance in Alzheimer patients: an open, controlled trial. Pharmacopsychiatry. 2003;36:304-8

Brassen S, Braus DF, Weber-Fahr W, Tost H, Moritz S, Adler G. (2004) Late-onset depression with mild cognitive deficits: electrophysiological evidences for a preclinical dementia syndrome. Dement. Geriatr. Cogn. Disord.; 18, 271-277.

Breslau J, Starr A, Sicotte N, Higa J, Buchsbaum MS. Topographic EEG changes with normal aging and SDAT. Electroencephalogr Clin Neurophysiol. 1989;72:281-9.

Briel RC, McKeith IG, Barker WA, Hewitt Y, Perry RH, Ince PG, Fairbairn AF. EEG findings in dementia with Lewy bodies and Alzheimer's disease. J Neurol Neurosurg Psychiatry. 1999;66:401-3.

Buscema M, Rossini P, Babiloni C, Grossi E. (2007) The IFAST model, a novel parallel nonlinear EEG analysis technique, distinguishes mild cognitive impairment and Alzheimer's disease patients with high degree of accuracy. Artif Intell Med.;40(2):127-41.

Buter TC, van den HA, Matthews FE, Larsen JP, Brayne C, Aarsland D. Dementia and survival in Parkinson disease: a 12-year population study. Neurology 2008; 70:1017-22.

Caviness JN, Hentz JG, Evidente VG, Driver-Dunckley E, Samanta J, Mahant P, Connor DJ, Sabbagh MN, Shill HA, Adler $\mathrm{CH}$. Both early and late cognitive dysfunction affects the electroencephalogram in Parkinson's disease. Parkinsonism Relat Disord. 2007 Aug;13(6):348-54. Epub 2007 Mar 8.

Caviness JN, Lue LF, Hentz JG, Schmitz CT, Adler CH1, Shill HA, Sabbagh MN, Beach TG, Walker DG.Cortical phosphorylated $\alpha$-Synuclein levels correlate with brain wave spectra in Parkinson's disease. Mov Disord. 2016 Jul;31(7):1012-9.

Claus JJ, Strijers RL, Jonkman EJ, Ongerboer de Visser BW, Jonker C, Walstra GJ, Scheltens P, van Gool WA. (1999) The diagnostic value of electroencephalography in mild senile Alzheimer's disease. Clin. Neurophysiol.; 110, 825-832. 
Cummings JL, Mega M, Gray K, Rosenberg-Thompson S, Carusi DA, Gornbein J. The neuropsychiatric inventory: comprehensive assessment of psychopathology in dementia. Neurology 1994;44:2308-14.

Crunelli V, David F, Lörincz ML, Hughes SW. The thalamocortical network as a single slow wave-generating unit. Curr Opin Neurobiol. 2015;31:72-80.

D'Amelio M, Rossini PM. Brain excitability and connectivity of neuronal assemblies in Alzheimer's disease: from animal models to human findings. Prog Neurobiol. 2012;99(1):42-60.

Dauwan $M$, van Dellen $E$, van Boxtel L, van Straaten EC, de Waal H, Lemstra AW, Gouw $A A$, van der Flier WM, Scheltens $P$, Sommer IE, Stam CJ. EEG-directed connectivity from posterior brain regions is decreased in dementia with Lewy bodies: a comparison with Alzheimer's disease and controls. Neurobiol Aging. 2016a May;41:122-9.

Dauwan M, van der Zande JJ, van Dellen E, Sommer IE, Scheltens P, Lemstra AW, Stam CJ. Random forest to differentiate dementia with Lewy bodies from Alzheimer's disease. Alzheimers Dement (Amst). 2016b Aug 19;4:99-106.

DeLong ER, DeLong DM, Clarke-Pearson DL. Comparing the areas under two or more correlated receiver operating characteristic curves: a nonparametric approach. Biometrics. 1988; 44(3):837-45.

Dierks T, Ihl R, Frolich L, Maurer K. Dementia of the Alzheimer type: effects on the spontaneous EEG described by dipole sources. Psychiatry Res 1993;50:151-162.

Dierks T, Jelic V, Pascual-Marqui RD, Wahlund LO, Julin P, Linden DEJ, Maurer K, Winblad $B$, Nordberg A. Spatial pattern of cerebral glucose metabolism (PET) correlates with localization of intracerebral EEG-generators in Alzheimer's disease. Clin Neurophysiol 2000; 111:1817-1824.

Dubois B, Pillon B. Cognitive deficits in Parkinson's disease. J Neurol 1997;244(1):2-8. Review.

Dubois B, Slachevsky A, Litvan I, Pillon B. The FAB: a frontal assessment battery at bedside. Neurology 2000;55, 1621e 1626.

Dubois B, Feldman HH, Jacova C, Hampel H, Molinuevo JL, Blennow K, DeKosky ST, Gauthier S, Selkoe D, Bateman R, Cappa S, Crutch S, Engelborghs S, Frisoni GB, Fox NC, Galasko D, Habert MO, Jicha GA, Nordberg A, Pasquier F, Rabinovici G, Robert P, Rowe C, Salloway S, Sarazin M, Epelbaum S, de Souza LC, Vellas B, Visser PJ, Schneider L, Stern Y, Scheltens $P$, Cummings JL. Advancing research diagnostic criteria for Alzheimer's disease: the IWG-2 criteria.Lancet Neurol. 2014; 13(6):614-29.

Delli Pizzi S, Franciotti R, Tartaro A, Caulo M, Thomas A, Onofrj M, Bonanni L. Structural alteration of the dorsal visual network in DLB patients with visual hallucinations: a cortical thickness MRI study. PLoS One. 2014;9(1):e86624.

Delli Pizzi S, Franciotti R, Taylor JP, Esposito R, Tartaro A, Thomas A, Onofrj M, Bonanni L. Structural Connectivity is Differently Altered in Dementia with Lewy Body and Alzheimer's Disease. Front Aging Neurosci. 2015;7:208. 
Delli Pizzi S, Franciotti R, Bubbico G, Thomas A, Onofrj M, Bonanni L. Atrophy of hippocampal subfields and adjacent extrahippocampal structures in dementia with Lewy bodies and Alzheimer's disease. Neurobiol Aging. 2016;40:103-9.

Dunkin JJ, Leuchter AF, Newton TF, Cook IA. Reduced EEG coherence in dementia: state or trait marker? Biol Psychiatry. 1994 Jun 1;35(11):870-9.

Dunkin JJ, Osato S, Leuchter AF. Relationships between EEG coherence and neuropsychological tests in dementia. Clin Electroencephalogr. 1995 Jan;26(1):47-59.

Ebert U, Kirch W. Scopolamine model of dementia: electroencephalogram findings and cognitive performance. Eur J Clin Invest. 1998 Nov;28(11):944-9. Review.

Emre M, Aarsland D, Brown R, Burn DJ, Duyckaerts C, Mizuno Y, et al. Clinical diagnostic criteria for dementia associated with Parkinson's disease. Mov Disord 2007;22:1689-707.

Engedal K, Snaedal J, Hoegh P, Jelic V, Bo Andersen B, Naik M, et al. Quantitative EEG applying the statistical recognition pattern method: a useful tool in dementia diagnostic workup. Dement Geriatr Cogn Disord. 2015;40(1-2):1-12.

Fahn S, Elton R, Members of the UPDRS Development Committee. Unified Parkinson's disease rating scale. In: Fahn S, Marsden CD, Calne DB, Goldstein M, editors. Recent Developments in Parkinson's Disease 1987; Vol. 2. Florham Park, NJ: Macmillan Health Care Information 1987; 293-304.

Fernandez A, Arrazola J, Maestu F, Amo C, Gil-Gregorio P, Wienbruch C, Ortiz T. Correlations of hippocampal atrophy and focal low-frequency magnetic activity in Alzheimer disease: volumetric MR imaging-magnetoencephalographic study. AJNR Am J Neuroradiol 2003;24(3):481-7.

Folstein MF, Folstein SE, McHugh PR. 'Mini Mental State': a practical method for grading the cognitive state of patients for clinician. J Psychiatr Res 1975; 12:189-98.

Fonseca LC, Tedrus GM, Prandi LR, Almeida AM, Furlanetto DS. Alzheimer's disease: relationship between cognitive aspects and power and coherence EEG measures. Arq Neuropsiquiatr. 2011 Dec;69(6):875-81.

Fonseca LC, Tedrus GM, Carvas PN, Machado EC. Comparison of quantitative EEG between patients with Alzheimer's disease and those with Parkinson's disease dementia. Clin Neurophysiol. 2013 Oct; 124(10):1970-4.

Fünfgeld EW. Computerised brain electrical activity findings of parkinson patients suffering from hyperkinetic side effects (hypersensitive dopamine syndrome) and a review of possible sources. J Neural Transm Suppl 1995;46:351-65.

Garn H, Coronel C, Waser M, Caravias G, Ransmayr G. Differential diagnosis between patients with probable Alzheimer's disease, Parkinson's disease dementia, or dementia with Lewy bodies and frontotemporal dementia, behavioral variant, using quantitative electroencephalographic features. J Neural Transm (Vienna). 2017 May;124(5):569-581.

Gelb DJ, Oliver E, Gilman S. Diagnostic criteria for Parkinson disease. Arch Neurol. 1999;56:33-9. 
Giaquinto S, Nolfe G. The EEG in the normal elderly: a contribution to the interpretation of aging and dementia. Electroencephalogr Clin Neurophysiol. 1986;63:540-6.

Gianotti LR, Künig G, Faber PL, Lehmann D, Pascual-Marqui RD, Kochi K, Schreiter-Gasser $U$. Rivastigmine effects on EEG spectra and three-dimensional LORETA functional imaging in Alzheimer's disease. Psychopharmacology (Berl). 2008 Jun;198(3):323-32.

Graff-Radford J, Lesnick TG, Boeve BF, Przybelski SA, Jones DT, Senjem ML, Gunter JL, Ferman TJ, Knopman DS, Murray ME, Dickson DW, Sarro L, Jack CR Jr, Petersen RC, Kantarci K. Predicting Survival in Dementia With Lewy Bodies With Hippocampal Volumetry. Mov Disord. 2016;31:989-94.

Hoehn MM, Yahr MD. Parkinsonism: onset, progression and mortality. Neurology 1967;17:427-42.

Huang C, Wahlund LO, Dierks T, Julin P, Winblad B, Jelic V. Discrimination of Alzheimer's disease and mild cognitive impairment by equivalent EEG sources: a cross-sectional and logitudinal study. Clin Neurophysiol 2000;11:1961-7.

Huber SJ, Shuttleworth EC, Freidenberg DL. Neuropsychological differences between the dementias of Alzheimer's and Parkinson's diseases. Arch Neurol 1989;46:1287-91.

Hughes CP, Berg L, Danziger WL, Coben LA, Martin RL. A new clinical scale for the staging of dementia. Br J Psychiatry 1982;140:566-72.

Hughes AM, Lynch P, Rhodes J, Ervine CM, Yates RA. Electroencephalographic and psychomotor effects of chlorpromazine and risperidone relative to placebo in normal healthy volunteers. Br J Clin Pharmacol. 1999 Sep;48(3):323-30.

Hughes TA, Ross HF, Musa S, Bhattacherjee S, Nathan RN, Mindham RH, Spokes EG. A 10year study of the incidence of and factors predicting dementia in Parkinson's disease. Neurology 2000;54:1596-602.

Hughes SW, Crunelli V. Thalamic mechanisms of EEG alpha rhythms and their pathological implications. Neuroscientist. 2005;11(4):357-372.

Irwin DJ, Grossman M, Weintraub D, Hurtig HI, Duda JE, Xie SX, Lee EB, Van Deerlin VM, Lopez OL, Kofler JK, Nelson PT, Jicha GA, Woltjer R, Quinn JF, Kaye J, Leverenz JB, Tsuang D, Longfellow K, Yearout D, Kukull W, Keene CD, Montine TJ, Zabetian CP, Trojanowski JQ. Neuropathological and genetic correlates of survival and dementia onset in synucleinopathies: a retrospective analysis. Lancet Neurol. 2017 Jan;16(1):55-65.

Jelic V, Julin P, Shigeta M, Nordberg A, Lannfelt L, Winblad B, et al. Apolipoprotein E epsilon4 allele decreases functional connectivity in Alzheimer's disease as measured by EEG coherence. J Neurol Neurosurg Psychiatry. 1997;63(1):59-65.

Jelic V, Johansson SE, Almkvist O, Shigeta M, Julin P, Nordberg A, Winblad B, Wahlund LO. Quantitative electroencephalography in mild cognitive impairment: longitudinal changes and possible prediction of Alzheimer's disease. Neurobiol Aging 2000;21:533-40.

Jeong J. EEG dynamics in patients with Alzheimer's disease. Clin Neurophysiol 2004;115:1490-505. 
Johannsson M, Snaedal J, Johannesson GH, Gudmundsson TE, Johnsen K. The acetylcholine index: an electroencephalographic marker of cholinergic activity in the living human brain applied to Alzheimer's disease and other dementias. Dement Geriatr Cogn Disord. 2015;39(3-4):132-42.

Jurica PJ, Leitten CL, Mattis S. Dementia Rating Scale-2: professional manual. Lutz: Psychological Assessment Resources; 2001.

Kai T, Asai Y, Sakuma K, Koeda T, Nakashima K.Quantitative electroencephalogram analysis in dementia with Lewy bodies and Alzheimer's disease. J Neurol Sci 2005;237:8995.

Kamei S, Morita A, Serizawa K, Mizutani T, Hirayanagi K. Quantitative EEG analysis of executive dysfunction in Parkinson disease. J Clin Neurophysiol 2010;27:193-7.

Kamiński MJ, Blinowska KJ. A new method of the description of the information flow in the brain structures. Biol Cybern. 1991;65(3):203-10.

Karantzoulis S, Galvin JE. Update on dementia with Lewy bodies. Curr Transl Geriatr Exp Gerontol Rep. 2013;2:196-204.

Klimesch W. Memory processes, brain oscillations and EEG synchronization. Int J Psychophysiol 1996;24:61-100.

Klimesch W, Doppelmayr M, Russegger H, Pachinger T, Schwaiger J. Induced alpha band power changes in the human EEG and attention. Neurosci Lett 1998;244:73-6.

Klimesch W. EEG alpha and theta oscillations reflect cognitive and memory performance: a review and analysis. Brain Research Reviews 1999; 29:1169-195.

Knott V, Mohr E, Mahoney C, Ilivitsky V. Electroencephalographic coherence in Alzheimer's disease: comparisons with a control group and population norms. J Geriatr Psychiatry Neurol. 2000;13(1):1-8.

Knyazeva MG, Jalili M, Brioschi A, Bourquin I, Fornari E, Hasler M, Meuli R, Maeder P, Ghika J. (2010 Jul) Topography of EEG multivariate phase synchronization in early Alzheimer's disease. Neurobiol Aging. 31(7):1132-44.

Kogan EA, Korczyn AD, Virchowsy RG, Klimovizky SSh, TrevesTA, Neufeld MY. EEG changes during long-term treatment with donepezil in Alzheimer's disease patients. J. Neural Transm. 2001; 108:1167-1173.

Lawton MP, Brodie EM. Assessment of older people: self maintaining and instrumental activity of daily living. J Gerontol 1969;9:179-86.

Lee DY, Lee KU, Kwon JS, Jang IJ, Cho MJ, Shin SG, Woo JI. Pharmacokineticpharmacodynamic modeling of risperidone effects on electroencephalography in healthy volunteers. Psychopharmacology (Berl). 1999 Jun;144(3):272-8.

Lehmann C, Koenig T, Jelic V, Prichep L, John RE, Wahlund LO, Dodge Y, Dierks T. (2007) Application and comparison of classification algorithms for recognition of Alzheimer's disease in electrical brain activity (EEG). J Neurosci. Methods; 161, 342-350. 
Leuchter AF, Spar JE, Walter DO, Weiner H. Electroencephalographic spectra and coherence in the diagnosis of Alzheimer's-type and multi-infarct dementia. A pilot study. Arch Gen Psychiatry. 1987 Nov;44(11):993-8.

Leuchter AF, Newton TF, Cook IA, Walter DO, Rosenberg-Thompson S, Lachenbruch PA. Changes in brain functional connectivity in Alzheimer-type and multi-infarct dementia. Brain. 1992 Oct;115 ( Pt 5):1543-61.

Leuchter AF, Dunkin JJ, Lufkin RB, Anzai Y, Cook IA, Newton TF. Effect of white matter disease on functional connections in the aging brain. J Neurol Neurosurg Psychiatry. 1994 Nov;57(11):1347-54.

Levy A, Brandeis R, Treves TA, Meshulam Y, Mawassi F, Feiler D, Wengier A, Glikfeld P, Grunwald J, Dachir S, et al. Transdermal physostigmine in the treatment of Alzheimer's disease. Alzheimer Dis Assoc Disord. 1994 Spring;8(1):15-21.

Levy G, Tang MX, Cote LJ, Louis ED, Alfaro B, Mejia H, Stern Y, Marder K. Motor impairment in PD: relationship to incident dementia and age. Neurology 2000;55:539-44.

Liem-Moolenaar M, de Boer P, Timmers M, Schoemaker RC, van Hasselt JG, Schmidt S, van Gerven JM. Pharmacokinetic-pharmacodynamic relationships of central nervous system effects of scopolamine in healthy subjects. $\mathrm{Br} J$ Clin Pharmacol. 2011a Jun;71(6):886-98.

Liem-Moolenaar M, Rad M, Zamuner S, Cohen AF, Lemme F, Franson KL, van Gerven JM, Pich EM. Central nervous system effects of the interaction between risperidone (single dose) and the 5-HT6 antagonist SB742457 (repeated doses) in healthy men. Br J Clin Pharmacol. 2011b Jun;71(6):907-16.

Lizio R, Del Percio C, Marzano N, Soricelli A, Yener GG, Başar E, Mundi C, De Rosa S, Triggiani Al, Ferri R, Arnaldi D, Nobili FM, Cordone S, Lopez S, Carducci F, Santi G, Gesualdo L, Rossini PM, Cavedo E, Mauri M, Frisoni GB, Babiloni C. Neurophysiological assessment of Alzheimer's disease individuals by a single electroencephalographic marker. J Alzheimers Dis. 2016;49(1):159-77. doi: 10.3233/JAD-143042.

Locatelli T, Cursi M, Liberati D, Franceschi M, Comi G. EEG coherence in Alzheimer's disease. Electroencephalogr Clin Neurophysiol. 1998;106(3):229-237.

Lörincz ML, Crunelli V, Hughes SW. Cellular dynamics of cholinergically induced alpha (8$13 \mathrm{~Hz}$ ) rhythms in sensory thalamic nuclei in vitro. J Neurosci. 2008;28(3):660-671.

Lörincz ML, Kékesi KA, Juhász G, Crunelli V, Hughes SW. Temporal framing of thalamic relay-mode firing by phasic inhibition during the alpha rhythm. Neuron. 2009;63(5):683696.

McKeith IG, Galasko D, Kosaka K, Perry EK, Dickson DW, Hansen LA, Salmon DP, Lowe J, Mirra SS, Byrne EJ, Lennox G, Quinn NP, Edwardson JA, Ince PG, Bergeron C, Burns A, Miller BL, Lovestone S, Collerton D, Jansen EN, Ballard C, de Vos RA, Wilcock GK, Jellinger $\mathrm{KA}$, Perry RH. Consensus guidelines for the clinical and pathologic diagnosis of dementia with Lewy bodies (DLB): report of the consortium on DLB international workshop. Neurology 1996;47:1113-24. 
McKeith IG, Dickson DW, Lowe J, Emre M, O'Brien JT, Feldman H, Cummings J, Duda JE, Lippa C, Perry EK, Aarsland D, Arai H, Ballard CG, Boeve B, Burn DJ, Costa D, Del Ser T, Dubois B, Galasko D, Gauthier S, Goetz CG, Gomez-Tortosa E, Halliday G, Hansen LA, Hardy J, Iwatsubo T, Kalaria RN, Kaufer D, Kenny RA, Korczyn A, Kosaka K, Lee VM, Lees A, Litvan I, Londos E, Lopez OL, Minoshima S, Mizuno Y, Molina JA, Mukaetova-Ladinska EB, Pasquier F, Perry RH, Schulz JB, Trojanowski JQ, Yamada M: Consortium on DLB. Diagnosis and management of dementia with Lewy bodies: third report of the DLB Consortium. Neurology 2005;65:1863-72.

McKeith IG, Boeve BF, Dickson DW, Halliday G, Taylor JP, Weintraub D, Aarsland D, Galvin J, Attems J, Ballard CG, Bayston A, Beach TG, Blanc F, Bohnen N, Bonanni L, Bras J, Brundin $P$, Burn D, Chen-Plotkin A, Duda JE, El-Agnaf O, Feldman H, Ferman TJ, Ffytche D, Fujishiro H, Galasko D, Goldman JG, Gomperts SN, Graff-Radford NR, Honig LS, Iranzo A, Kantarci K, Kaufer D, Kukull W, Lee VMY, Leverenz JB, Lewis S, Lippa C, Lunde A, Masellis M, Masliah E, McLean P, Mollenhauer B, Montine TJ, Moreno E, Mori E, Murray M, O'Brien JT, Orimo S, Postuma RB, Ramaswamy S, Ross OA, Salmon DP, Singleton A, Taylor A, Thomas A, Tiraboschi P, Toledo JB, Trojanowski JQ, Tsuang D, Walker Z, Yamada M, Kosaka K. Diagnosis and management of dementia with Lewy bodies: Fourth consensus report of the DLB Consortium. Neurology. 2017 Jun 7.

McKhann G, Drachman D, Folstein M, Katzman R, Price D, Stadlan EM. Clinical diagnosis of Alzheimer's disease: report of the NINCDS-ADRDA Work Group under the auspices of Department of Health and Human Services Task Force on Alzheimer's Disease. Neurology 1984;34:939-44.

McKhann GM, Knopman DS, Chertkow H, Hyman BT, Jack CR Jr, Kawas CH, Klunk WE, Koroshetz WJ, Manly JJ, Mayeux R, Mohs RC, Morris JC, Rossor MN, Scheltens P, Carrillo MC, Thies B, Weintraub S, Phelps CH. The diagnosis of dementia due to Alzheimer's disease: recommendations from the National Institute on Aging-Alzheimer's Association workgroups on diagnostic guidelines for Alzheimer's disease. Alzheimers Dement. 2011;7:263-9.

Melgari JM, Curcio G, Mastrolilli F, Salomone G, Trotta L, Tombini M, di Biase L, Scrascia F, Fini R, Fabrizio E, Rossini PM, Vernieri F. Alpha and beta EEG power reflects L-dopa acute administration in parkinsonian patients.Front Aging Neurosci. 2014;6:302.

Missonnier P, Gold G, Herrmann FR, Fazio-Costa L, Michel JP, Deiber, MP, Michon A, Giannakopoulos P. (2006) Decreased theta event-related synchronization during working memory activation is associated with progressive mild cognitive impairment. Dement. Geriatr. Cogn. Disord. 22, 250-259.

Moazami-Goudarzi M, Sarnthein J, Michels L, Moukhtieva R, Jeanmonod D. Enhanced frontal low and high frequency power and synchronization in the resting EEG of parkinsonian patients. Neuroimage. 2008 Jul 1; 41(3):985-97.

Moretti DV, Babiloni F, Carducci F, Cincotti F, Remondini E, Rossini PM, Salinari S, Babiloni C. Computerized processing of EEG-EOG-EMG artifacts for multicentric studies in EEG oscillations and event-related potentials. Int J Pshycophysiol 2003;47:199-216. 
Morita A, Kamei S, Serizawa K, Mizutani T. The relationship between slowing EEGs and the progression of Parkinson's disease. J Clin Neurophysiol. 2009 Dec;26(6):426-9.

Morita A, Kamei S, Mizutani T. Relationship between slowing of the EEG and cognitive impairment in Parkinson disease. J Clin Neurophysiol. 2011 Aug;28(4):384-7.

Neufeld MY, Inzelberg R, Korczyn AD. EEG in demented and non-demented parkinsonian patients. Acta Neurol Scand 1988;78:1-5.

Neufeld MY, Rabey MJ, Parmet Y, Sifris P, Treves TA, Korczyn AD. Effects of a single intravenous dose of scopolamine on the quantitative EEG in Alzheimer's disease patients and age-matched controls. Electroencephalogr Clin Neurophysiol. 1994 Dec;91(6):407-12.

Niedermeyer E, Naidu SB, Plate C. Unusual EEG theta rhythms over central region in Rett syndrome: considerations of the underlying dysfunction. Clin Electroencephalogr 1997;28:36-43.

Nuwer M. (1997) Assessment of digital EEG, quantitative EEG and brain mapping: report of the American Clinical Neurophysiology Society. Neurology (1997); 49, 277-292.

Olichney JM, Iragui VJ, Kutas M, Nowacki R, Morris S, Jeste DV. Relationship between auditory P300 amplitude and age of onset of schizophrenia in older patients. Psychiatry Res. 1998 Jul 13;79(3):241-54.

Onofrj M, Thomas A, lacono D, Luciano AL, Di lorio A. The effects of a cholinesterase inhibitor are prominent in patients with fluctuating cognition: a part 3 study of the main mechanism of cholinesterase inhibitors in dementia. Clin. Neuropharmacol. 2003;26:239251.

Pascual-Marqui, R. D. (2007a). Discrete, 3D distributed, linear imaging methods of electric neuronal activity. Part 1: exact, zero error localization. arXiv:0710.3341 [math-ph] Available at: http://arxiv.org/pdf/0710.3341. [Accessed November 19, 2015].

Pascual-Marqui, R. D. (2007b). Coherence and phase synchronization: generalization to pairs of multivariate time series, and removal of zero-lag contributions. arXiv:0706.1776v3 [stat.ME]. Available at: http://arxiv.org/pdf/0706.1776. [Accessed November 19, 2015].

Pascual-Marqui, R. D. (2007c). Instantaneous and lagged measurements of linear and nonlinear dependence between groups of multivariate time series: frequency decomposition. arXiv:0711.1455 [stat.ME]. Available at: http://arxiv.org/abs/0711.1455. [Accessed November 19, 2015].

Pascual-Marqui, R. D., Lehmann, D., Koukkou, M., Kochi, K., Anderer, P., Saletu, B., et al. (2011). Assessing interactions in the brain with exact low-resolution electromagnetic tomography. Philos Trans A Math Phys Eng Sci. 369, 3768-84. doi: 10.1098/rsta.2011.0081.

Pascual-Marqui RD, Biscay RJ, Bosch-Bayard J, Lehmann D, Kochi K, Kinoshita T, Yamada $\mathrm{N}$, Sadato N. Assessing direct paths of intracortical causal information flow of oscillatory activity with the isolated effective coherence (iCoh). Front Hum Neurosci. 2014 Jun 20;8:448. 
Passero S, Rocchi R, Vatti G, Burgalassi L, Battistini N. Quantitative EEG mapping, regional cerebral blood flow, and neuropsychological function in Alzheimer's disease. Dementia 1995;6(3):148-56.

Peavy GM, Edland SD, Toole BM, Hansen LA, Galasko DR, Mayo AM. Phenotypic differences based on staging of Alzheimer's neuropathology in autopsy-confirmed dementia with Lewy bodies. Parkinsonism Relat Disord. 2016 Oct;31:72-78.

Pievani M, de Haan W, Wu T, Seeley WW, Frisoni GB. Functional network disruption in the degenerative dementias. Lancet Neurol. 2011 Sep;10(9):829-43.

Pogarell O, Teipel SJ, Juckel G, Gootjes L, Moller T, Burger K, et al. EEG coherence reflects regional corpus callosum area in Alzheimer's disease. J Neurol Neurosurg Psychiatry. 2005;76(1):109-111.

Pollok B, Kamp D, Butz M, Wojtecki L, Timmermann L, Südmeyer M, Krause V, Schnitzler A. Increased SMA-M1 coherence in Parkinson's disease - Pathophysiology or compensation? Exp Neurol. 2013 Sep;247:178-81.

Ponomareva NV, Selesneva ND, Jarikov GA. EEG alterations in subjects at high familial risk for Alzheimer's disease. Neuropsychobiology 2003;48:152-9.

Pugnetti L, Baglio F, Farina E, Alberoni M, Calabrese E, Gambini A, Di Bella E, Garegnani M, Deleonardis L, Nemni R. EEG evidence of posterior cortical disconnection in PD and related dementias. Int J Neurosci 2010;120:88-98.

Reeves RR., Struve FA, Patrick G. The effects of donepezil on quantitative EEG in patients with Alzheimer's disease. Clin. Electroencephalogr. 2002; 33:93-96.

Reuter-Lorenz PA, Mikels JA. A split-brain model of Alzheimer's disease? Behavioral evidence for comparable intra and interhemispheric decline. Neuropsychologia. 2005;43(9):1307-17.

Rodriguez G, Copello F, Nobili F, Vitali P, Perego G, Nobili F. EEG spectral profile to stage Alzheimer's disease. Clin Neurophysiol 1999;110:1831-7.

Rodriguez G, Vitali P, De Leo C, De Carli F, Girtler N, Nobili F. Quantitative EEG changes in Alzheimer patients during long-term donepezil therapy. Neuropsychobiology 2002;46:4956.

Roks G, Korf ES, van der Flier WM, Scheltens P, Stam CJ. The use of EEG in the diagnosis of dementia with Lewy bodies. J Neurol Neurosurg Psychiatry. 2008;79(4):377-380.

Roman GC, Tatemichi TK, Erkinjuntti T, Cummings JL, Masdeu JC, Garcia JH, Amaducci L, Orgogozo JM, Brun A, Hofman A, et al. Vascular dementia: diagnostic criteria for research studies. Report of the NINDS-AIREN International Workshop. Neurology 1993;43:250-60.

Rosen WG, Terry RD, Fuld PA, Katzman R, Peck A. Pathological verification of ischemic score in differentiation of dementias. Ann Neurol 1980;7:486-8.

Roy R, Niccolini F, Pagano G, Politis M. Cholinergic imaging in dementia spectrum disorders. Eur J Nucl Med Mol Imaging. 2016 Jul;43(7):1376-86. 
Sankari Z, Adeli H, Adeli A. Intrahemispheric, interhemispheric, and distal EEG coherence in Alzheimer's disease. Clin Neurophysiol. 2011;122(5):897-906.

Sarro L, Senjem ML, Lundt ES, Przybelski SA, Lesnick TG, Graff-Radford J, Boeve BF, Lowe VJ, Ferman TJ, Knopman DS, Comi G, Filippi M, Petersen RC, Jack CR Jr, Kantarci K. Amyloid- $\beta$ deposition and regional grey matter atrophy rates in dementia with Lewy bodies. Brain. 2016 pii: aww193. [Epub ahead of print].

Serizawa K, Kamei S, Morita A, Hara M, Mizutani T, Yoshihashi H, Yamaguchi M, Takeshita J, Hirayanagi K. Comparison of quantitative EEGs between Parkinson disease and ageadjusted normal controls. J Clin Neurophysiol 2008;25:361-6.

Silberstein P, Pogosyan A, Kühn AA, Hotton G, Tisch S, Kupsch A, Dowsey-Limousin P, Hariz MI, Brown P. Cortico-cortical coupling in Parkinson's disease and its modulation by therapy. Brain. 2005 Jun;128(Pt 6):1277-91.

Sloan EP, Fenton GW, Kennedy NS, MacLennan JM. Neurophysiology and SPECT cerebral blood flow patterns in dementia. Electroencephalogr Clin Neurophysiol. 1994;91(3):163170.

Snaedal J, Johannesson GH, Gudmundsson TE, Blin NP, Emilsdottir AL, Einarsson B, et al. Diagnostic accuracy of statistical pattern recognition of electroencephalogram registration in evaluation of cognitive impairment and dementia. Dement Geriatr Cogn Disord. 2012;34(1):51-60.

Snaedal J, Johannesson GH, Gudmundsson TE, Gudmundsson S, Pajdak TH, Johnsen K. The use of EEG in Alzheimer's disease, with and without scopolamine - a pilot study. Clin Neurophysiol. 2010 Jun;121(6):836-41.

Soikkeli R, Partanen J, Soininen H, Pääkkönen A, Riekkinen Sr P. Slowing of EEG in Parkinson's disease. Electroencephalogr Clin Neurophysiol 1991;79:159-65.

Stam CJ, Jones BF, Manshanden I, van Cappellen van Walsum AM, Montez T, Verbunt JP, de Munck JC, van Dijk BW, Berendse HW, Scheltens P. Magnetoencephalographic evaluation of resting-state functional connectivity in Alzheimer's disease. Neuroimage 2006;32:1335-44.

Stern Y. An approach to studying the neural correlates of reserve. Brain Imaging Behav. 2017 Apr;11(2):410-416.

Taylor H, Schmiedt JT, Carcak N, Onat F, Di Giovanni G, Lambert R, et al. Investigating local and long-range neuronal network dynamics by simultaneous optogenetics, reverse microdialysis and silicon probe recordings in vivo. J Neurosci Methods. 2014; 235:83-91.

Teipel S, Grothe MJ, Zhou J, Sepulcre J, Dyrba M, Sorg C, Babiloni C. Measuring Cortical Connectivity in Alzheimer's Disease as a Brain Neural Network Pathology: Toward Clinical Applications. J Int Neuropsychol Soc. 2016 Feb;22(2):138-63.

Teramoto H, Morita A, Ninomiya S, Akimoto T, Shiota H, Kamei S. Relation between Resting State Front-Parietal EEG Coherence and Executive Function in Parkinson's Disease. Biomed Res Int. 2016;2016:2845754. 
The World Alzheimer Report 2015, The Global Impact of Dementia: An analysis of prevalence, incidence, cost and trends. 2015

Valladares-Neto DC, Buchsbaum MS, Evans WJ, Nguyen D, Nguyen P, Siegel BV, Stanley J, Starr A, Guich S, Rice D. EEG delta, positron emission tomography, and memory deficit in Alzheimer's disease. Neuropsychobiology. 1995;31:173-81.

van Dellen E, de Waal H, van der Flier WM, Lemstra AW, Slooter AJ, Smits LL, van Straaten EC, Stam CJ, Scheltens P. Loss of EEG Network Efficiency Is Related to Cognitive Impairment in Dementia With Lewy Bodies. Mov Disord. 2015 Nov;30(13):1785-93

Walker MP, Ayre GA, Cummings JL, Wesnes K, McKeith IG, O'Brien JT, Ballard CG. The clinician assessment of fluctuation and the one day fluctuation assessment scale. Two methods to assess fluctuating confusion in dementia. Br. J. Psychiatry 2000a; 177, 252e 256.

Walker MP, Ayre GA,Cummings JL, Wesnes K, Mc Keith IG,O'Brien JT, Ballard CG. Quantifying fluctuation in dementia with Lewy bodies, Alzheimer's disease, and vascular dementia. Neurology 2000b; 54:1616-25.

Walker Z, Possin KL, Boeve BF, Aarsland D.Lewy body dementias. Lancet. 2015;386:168397.Review

Wolters EC. Intrinsic and extrinsic psychosis in Parkinson's disease. J Neurol 2001;248(Suppl. 3). Review.

Yesavage JA, Brink TL, Rose TL, Lum O, Huang V, Adey M, Leirer VO. Development and validation of a geriatric depression screening scale: a preliminary report. J Psychiatr Res. 1983;17(1):37-49 


\section{Table legends}

Table 1. Mean values ( \pm standard error mean, $S E$ ) of the demographic and clinical data as well as the results of their statistical comparisons $(p<0.05)$ in the groups of normal healthy elderly (Nold) subjects and patients with dementia due to Alzheimer's disease $(A D D)$, Parkinson's disease (PDD), and Lewy bodies (DLB). Legend: MMSE = Mini Mental State Evaluation; $M / F=$ males $/$ females; $n . s .=$ not significant $(p>0.05)$.

Table 2. Talairach coordinates of the centroid voxel for the left and right frontal, central, parietal, occipital and temporal regions of interest (ROIs)

Table 3. Mean values ( \pm SE) of transition frequency (TF) and individual alpha frequency (IAF) peak of the rsEEG power density spectra in the Nold, ADD, PDD, and DLB groups. The Table also reports the $p$-values derived from the statistical comparisons of these values between the groups. See the Methods section for a definition of the TF and IAF. Legend: ADD, Alzheimer's disease with dementia; PDD, Parkinson's disease with dementia; DLB, dementia with Lewy body; rsEEG, resting state eyes-closed electroencephalographic; SE, standard error of the mean.

Table 4. Results of the classification among Nold, ADD, PDD, and DLB individuals based on the lagged linear connectivity (LLC) solutions computed in eLORETA cortical sources of resting state electroencephalographic (rSEEG) rhythms at individual delta and alpha frequency bands. These LLC solutions were those showing statistically significant differences among the four groups in the main statistical analysis (i.e. Nold, ADD, PDD, DLB). The classification rate is computed by the analysis of area under the receiver operating characteristic (AUROC) curve. The table reports the classification indexes (Sensitivity, Specificity, Accuracy) for all the LLC solutions in delta and alpha sources having a value higher than 0.70 in the AUROC curves. Highlighted in red type are the best classification results for each LLC solutions in the classifications of interest, namely Nold vs. ADD individuals, Nold vs. DLB individuals, and Nold vs. PDD individuals.

Table 5 Duncan post-hoc relative to a statistically significant main effect ( $F=35.9, p<$ 0.00001) for the factor Pair of ROIs (frontal-central, frontal-temporal, central-temporal, frontal-parietal, central-parietal, temporal-parietal, frontal-occipital, central-occipital, temporal-occipital, and parietal-occipital) in an ANOVA design focused on the intrahemispheric LLC solutions computed in eLORETA cortical sources of alpha rsEEG rhythms of the Nold group ( $p<0.05)$. 


\section{Figure legends}

Figure 1. Representative EEG waveforms (10 s) on Fz and Pz scalp electrodes for Nold, $A D D, P D D$, and DLB subjects. These subjects were carefully selected to represent the general features of EEG waveforms in the groups of individuals investigated in the present study.

Figure 2. Mean values ( \pm standard error mean, SE) of the interhemispheric lagged linear connectivity (LLC) solutions computed in eLORETA cortical sources of resting state electroencephalographic rhythms ( $r S E E G$ ) relative to a statistically significant ANOVA interaction effect $(F=3.2, p<0.0001)$ among the factors Group (Nold, ADD, PDD, and DLB), Band (delta, theta, alpha 1, alpha 2, alpha 3, beta 1, beta 2, and gamma), and Region of interest, ROI (frontal, central, parietal, occipital, and temporal). Legend: the rectangles indicate the ROIs and frequency bands in which the interhemispheric LLC solutions presented statistically significant differences among the four groups of subjects $(p<0.05)$.

Figure 3. Mean values $( \pm S E$ ) of the Intrahemispheric LLC solutions computed in eLORETA cortical sources of rSEEG rhythms relative to a statistically significant ANOVA interaction effect $(F=5.4, p<0.0001$ ) among the factors Group (Nold, ADD, PDD, and DLB), Band (delta, theta, alpha 1 , alpha 2 , alpha 3 , beta 1 , beta 2 , and gamma), and ROI (frontal, central, parietal, occipital, and temporal). Legend: the rectangles indicate the ROIs and frequency bands in which the Intrahemispheric LLC solutions presented statistically significant differences among the four groups of subjects $(p<0.05)$.

Figure 4. Individual values of the interhemispheric LLC solutions computed in eLORETA cortical sources of alpha rhythms showing statistically significant $(p<0.05)$ differences between the Nold, ADD, PDD, and DLB groups (i.e. parietal, occipital, and temporal alpha 2; parietal, occipital, and temporal alpha 3). Noteworthy, the Grubbs' test showed no outliers from those individual values of the interhemispheric LLC solutions (arbitrary threshold of $p<0.0001$ ).

Figure 5. Individual values of the intrahemispheric LLC solutions computed in eLORETA cortical sources of alpha rhythms showing statistically significant $(p<0.05)$ differences between the Nold, ADD, PDD, and DLB groups (i.e. frontal, central, parietal, occipital, and temporal alpha 2; central, parietal, occipital, and temporal alpha 3). Noteworthy, the Grubbs' test showed no outliers from those individual values of the intra-hemispherical LLC of eLORETA rsEEG cortical sources (arbitrary threshold of $p<0.0001$ ).

Figure 6. Scatterplots showing the correlation between LLC solutions of computed in eLORETA cortical sources of alpha rhythms and the MMSE score in the Nold, ADD, PDD, and DLB subjects as a whole group. The Spearman test evaluated the hypothesis of that correlation (Bonferroni's correction at $p<0.05$ ). The $r$ and $p$ values are reported within the diagram.

Figure 7. (Top): Receiver operating characteristic (ROC) curve illustrating the classification of the ADD and Nold individuals based on the interhemispheric LLC solutions computed in 
temporal alpha 2 cortical sources. The area under the ROC (AUROC) curve was 0.84 (e.g. 1 $=100 \%$ ), indicating a good classification accuracy for the ADD and Nold individuals. (Middle): ROC curve illustrating the classification of the PDD and Nold individuals based on the interhemispheric LLC solutions computed in temporal alpha 3 cortical sources. The AUROC was 0.72 , indicating a moderate classification accuracy of the PDD and Nold individuals. (Bottom): ROC curve illustrating the classification of the DLB and Nold individuals based on the intrahemispheric LLC solutions computed in central alpha 2 cortical sources. The AUROC was 0.78 , indicating a moderate classification accuracy of the DLB and Nold individuals.

Figure 8. $(A)$ : Mean values ( $\pm S E$ ) of the Intrahemispheric LLC solutions computed in eLORETA cortical sources of alpha rSEEG rhythms relative to a statistically significant main effect $(F=35.9, p<0.00001$ ) for the factor Pair of ROIs (frontal-central, frontal-temporal, central-temporal, frontal-parietal, central-parietal, temporal-parietal, frontal-occipital, central-occipital, temporal-occipital, and parietal-occipital) in Nold subjects. (B): Mean values $( \pm \mathrm{SE}$ ) of the intrahemispheric LLC solutions computed in eLORETA cortical sources of alpha rsEEG rhythms relative to a statistically significant ANOVA interaction effect ( $F=$ 5.7, $p<0.00001$ ) among the factors Group (Nold and ADD), and Pair of ROls (frontalcentral, frontal-temporal, central-temporal, frontal-parietal, central-parietal, temporalparietal, frontal-occipital, central-occipital, temporal-occipital, and parietal-occipital). Legend: the rectangles indicate the Pair of ROIs which the intrahemispheric LLC solutions presented statistically significant differences between Nold and ADD groups $(p<0.05)$. (C): Mean values ( \pm SE) of the Intrahemispheric LLC solutions computed in eLORETA cortical sources of alpha rSEEG rhythms relative to a statistically significant ANOVA interaction effect $(F=2.5, p<0.01$ ) among the factors Group (Nold and PDD), and Pair of ROIs (frontal-central, frontal-temporal, central-temporal, frontal-parietal, central-parietal, temporal-parietal, frontal-occipital, central-occipital, temporal-occipital, and parietaloccipital). Legend: the rectangles indicate the Pair of ROIs which the intrahemispheric LLC solutions presented statistically significant differences between Nold and PDD groups $(p<$ $0.05)$. (D): Mean values ( $\pm S E$ ) of the intrahemispheric LLC solutions computed in eLORETA cortical sources of alpha rsEEG rhythms relative to a statistically significant ANOVA interaction effect $(F=4.2, p<0.00005)$ among the factors Group (Nold and DLB), and Pair of ROIs (frontal-central, frontal-temporal, central-temporal, frontal-parietal, centralparietal, temporal-parietal, frontal-occipital, central-occipital, temporal-occipital, and parietal-occipital). Legend: the rectangles indicate the Pair of ROls which the intrahemispheric LLC solutions presented statistically significant differences between Nold and DLB groups $(p<0.05)$. 
Table 1

\begin{tabular}{|c|c|c|c|c|c|}
\hline \multicolumn{6}{|c|}{$\begin{array}{l}\text { MEAN VALUES ( } \pm \text { STANDARD ERROR MEAN, SE) OF DEMOGRAPHIC DATA AND GLOBAL } \\
\text { COGNITIVE STATUS (MMSE SCORE ) }\end{array}$} \\
\hline & Nold & ADD & PDD & DLB & Statistical analysis \\
\hline $\mathbf{N}$ & 40 & 42 & 42 & 34 & \\
\hline Age & $\begin{aligned} & 72.9 \\
&( \pm 1.1 \mathrm{SE})\end{aligned}$ & $\begin{aligned} & 73.3 \\
&( \pm 1.0 \mathrm{SE})\end{aligned}$ & $\begin{array}{c}74.1 \\
( \pm 1.1 \mathrm{SE})\end{array}$ & $\begin{aligned} & 75.1 \\
&( \pm 1.1 \mathrm{SE})\end{aligned}$ & ANOVA: n.s. \\
\hline $\begin{array}{l}\text { Gender } \\
\text { (M/F) }\end{array}$ & $16 / 24$ & $17 / 25$ & $18 / 24$ & $11 / 23$ & Kruskal-Wallis: n.s. \\
\hline Education & $\begin{aligned} & 8.5 \\
&( \pm 0.6 \mathrm{SE})\end{aligned}$ & $\begin{aligned} & 8.1 \\
&( \pm 0.8 \mathrm{SE})\end{aligned}$ & $\begin{array}{l}7.0 \\
( \pm 0.6 \mathrm{SE})\end{array}$ & $\begin{aligned} & 7.4 \\
&( \pm 0.8 \mathrm{SE})\end{aligned}$ & ANOVA: n.s. \\
\hline MMSE & $\begin{aligned} & 28.7 \\
&( \pm 0.2 \mathrm{SE})\end{aligned}$ & $\begin{array}{c}18.9 \\
( \pm 0.6 \mathrm{SE})\end{array}$ & $\begin{array}{c}18.8 \\
( \pm 0.7 \mathrm{SE})\end{array}$ & $\begin{array}{c}18.6 \\
( \pm 0.8 \mathrm{SE})\end{array}$ & $\begin{array}{l}\text { Kruskal-Wallis: } \mathrm{H}=88.7, \\
\mathrm{p}<0.00001 \\
\text { (Nold }>A D D, P D D, D L B)\end{array}$ \\
\hline
\end{tabular}


Table 2

\begin{tabular}{|c|c|c|c|}
\hline Regions of interest (ROIs) & X & Y & Z \\
\hline Left frontal & -27.9 & 35.2 & 10.6 \\
\hline Left central & -32.6 & -12.7 & 52.3 \\
\hline Left parietal & -33.2 & -53.4 & 39.9 \\
\hline Left occipital & -22.2 & -81.0 & 5.2 \\
\hline Left temporal & -49.6 & -22.9 & -13.9 \\
\hline Right frontal & 27.8 & 35.4 & 12.3 \\
\hline Right central & 32.5 & -12.4 & 52.5 \\
\hline Right parietal & 30.2 & -53.5 & 40.9 \\
\hline Right occipital & 20.4 & -81.5 & 5.1 \\
\hline Right temporal & 50.2 & -21.1 & -14.2 \\
\hline
\end{tabular}


Table 3

MEAN VALUES ( \pm SE) OF TRANSITION THETA/ALPHA FREQUENCY (TF) AND INDIVIDUAL ALPHA FREQUENCY (IAF) PEAK

\begin{tabular}{|c|c|c|c|c|c|}
\hline & Nold & ADD & PDD & DLB & Statistical analysis \\
\hline TF & $\begin{array}{c}5.8 \\
( \pm 0.2 \mathrm{SE})\end{array}$ & $\begin{array}{c}5.9 \\
( \pm 0.2 \mathrm{SE})\end{array}$ & $\begin{array}{c}4.9 \\
( \pm 0.2 \mathrm{SE})\end{array}$ & $\begin{array}{c}5.0 \\
( \pm 0.2 \mathrm{SE})\end{array}$ & $\begin{array}{c}\text { ANOVA: } F=10.4, p<0.00001 \\
\text { (Nold, } A D D>P D D, D L B)\end{array}$ \\
\hline IAF & $\begin{array}{c}9.0 \\
( \pm 0.2 \mathrm{SE})\end{array}$ & $\begin{array}{c}8.8 \\
( \pm 0.3 \mathrm{SE})\end{array}$ & $\begin{array}{c}7.3 \\
( \pm 0.3 \mathrm{SE})\end{array}$ & $\begin{array}{c}7.3 \\
( \pm 0.3 \mathrm{SE})\end{array}$ & $\begin{array}{c}\text { ANOVA: } F=14.9, p<0.00001 \\
\text { (Nold }>\text { ADD }>\text { PDD, DLB) }\end{array}$ \\
\hline
\end{tabular}


Table 4

\begin{tabular}{|c|c|c|c|c|c|}
\hline \multicolumn{6}{|c|}{$\begin{array}{c}\text { CLASSIFICATION OF NOLD, ADD, PDD, AND DLB INDIVIDUALS BASED ON LAGGED LINEAR } \\
\text { CONNECTIVIY OF rSEEG CORTICAL SOURCES }\end{array}$} \\
\hline \multirow{17}{*}{$\begin{array}{l}\text { Nold vs. } \\
\text { ADD }\end{array}$} & Lagged linear connectivity (LLC) & Sensitivity & Specificity & Accuracy & AUROC \\
\hline & Occipital delta interhemispheric & $61.9 \%$ & $77.5 \%$ & $69.7 \%$ & 0.70 \\
\hline & Parietal alpha 2 interhemispheric & $83.3 \%$ & $67.5 \%$ & $75.4 \%$ & 0.76 \\
\hline & Occipital alpha 2 interhemispheric & $61.9 \%$ & $80 \%$ & $71 \%$ & 0.74 \\
\hline & Temporal alpha 2 interhemispheric & $85.7 \%$ & $67.5 \%$ & $76.6 \%$ & 0.81 \\
\hline & Parietal alpha 3 interhemispheric & $73.8 \%$ & $72.5 \%$ & $73.2 \%$ & 0.79 \\
\hline & Occipital alpha 3 interhemispheric & $88.1 \%$ & $62.5 \%$ & $75.3 \%$ & 0.77 \\
\hline & Temporal alpha 3 interhemispheric & $78.6 \%$ & $77.5 \%$ & $78.1 \%$ & 0.84 \\
\hline & Frontal alpha 2 intrahemispheric & $57.1 \%$ & $85.0 \%$ & $71.1 \%$ & 0.73 \\
\hline & Central alpha 2 intrahemispheric & $69.1 \%$ & $82.5 \%$ & $75.8 \%$ & 0.77 \\
\hline & Parietal alpha 2 intrahemispheric & $71.4 \%$ & $77.5 \%$ & $74.5 \%$ & 0.77 \\
\hline & Occipital alpha 2 intrahemispheric & $69.1 \%$ & $80.0 \%$ & $74.5 \%$ & 0.75 \\
\hline & Temporal alpha 2 intrahemispheric & $69.1 \%$ & $80.0 \%$ & $74.5 \%$ & 0.74 \\
\hline & Central alpha 3 intrahemispheric & $64.3 \%$ & $87.5 \%$ & $75.9 \%$ & 0.79 \\
\hline & Parietal alpha 3 intrahemispheric & $61.9 \%$ & $87.5 \%$ & $74.7 \%$ & 0.79 \\
\hline & Occipital alpha 3 intrahemispheric & $64.3 \%$ & $82.5 \%$ & $73.4 \%$ & 0.77 \\
\hline & Temporal alpha 3 intrahemispheric & $47.6 \%$ & $95.0 \%$ & $71.3 \%$ & 0.77 \\
\hline \multirow{2}{*}{$\begin{array}{l}\text { Nold vs. } \\
\text { PDD }\end{array}$} & Temporal alpha 2 interhemispheric & $82.3 \%$ & $70 \%$ & $76.2 \%$ & 0.75 \\
\hline & Temporal alpha 3 interhemispheric & $73.8 \%$ & $65 \%$ & $69.4 \%$ & 0.72 \\
\hline \multirow{12}{*}{$\begin{array}{l}\text { Nold vs. } \\
\text { DLB }\end{array}$} & Parietal alpha 2 interhemispheric & $82.4 \%$ & $67.5 \%$ & $74.9 \%$ & 0.76 \\
\hline & Temporal alpha 2 interhemispheric & $76.5 \%$ & $67.5 \%$ & $72 \%$ & 0.72 \\
\hline & Parietal alpha 3 interhemispheric & $79.4 \%$ & $70.0 \%$ & $74.7 \%$ & 0.75 \\
\hline & Temporal alpha 3 interhemispheric & $91.2 \%$ & $57.5 \%$ & $74.3 \%$ & 0.77 \\
\hline & Central alpha 2 intrahemispheric & $83.5 \%$ & $65 \%$ & $74.3 \%$ & 0.78 \\
\hline & Parietal alpha 2 intrahemispheric & $73.5 \%$ & $77.5 \%$ & $75.5 \%$ & 0.77 \\
\hline & Occipital alpha 2 intrahemispheric & $70.6 \%$ & $75.0 \%$ & $72.8 \%$ & 0.75 \\
\hline & Temporal alpha 2 intrahemispheric & $85.3 \%$ & $57.5 \%$ & $71.4 \%$ & 0.74 \\
\hline & Central alpha 3 intrahemispheric & $73.5 \%$ & $72.5 \%$ & $73.0 \%$ & 0.76 \\
\hline & Parietal alpha 3 intrahemispheric & $94.1 \%$ & $60.0 \%$ & $77.1 \%$ & 0.77 \\
\hline & Occipital alpha 3 intrahemispheric & $70.6 \%$ & $70.0 \%$ & $70.3 \%$ & 0.74 \\
\hline & Temporal alpha 3 intrahemispheric & $76.5 \%$ & $65.0 \%$ & $70.7 \%$ & 0.75 \\
\hline
\end{tabular}




\section{Table 5}

\begin{tabular}{|c|c|c|c|c|c|c|c|c|c|c|}
\hline & $\begin{array}{l}\text { Frontal- } \\
\text { Central }\end{array}$ & $\begin{array}{l}\text { Frontal- } \\
\text { Temporal }\end{array}$ & $\begin{array}{l}\text { Central- } \\
\text { Temporal }\end{array}$ & $\begin{array}{l}\text { Frontal- } \\
\text { Parietal }\end{array}$ & $\begin{array}{l}\text { Central- } \\
\text { Parietal }\end{array}$ & $\begin{array}{c}\text { Temporal- } \\
\text { Parietal } \\
\end{array}$ & $\begin{array}{l}\text { Frontal- } \\
\text { Occipital }\end{array}$ & $\begin{array}{l}\text { Central- } \\
\text { Occipital }\end{array}$ & $\begin{array}{c}\text { Temporal- } \\
\text { Occipital }\end{array}$ & $\begin{array}{l}\text { Parietal } \\
\text { Occipital }\end{array}$ \\
\hline $\begin{array}{l}\text { Frontal- } \\
\text { Central }\end{array}$ & & $<0.001$ & $<0.00001$ & n.s. & $<0.00001$ & $<0.00001$ & n.s. & $<0.00001$ & $<0.00001$ & $<0.00001$ \\
\hline $\begin{array}{l}\text { Frontal- } \\
\text { Temporal }\end{array}$ & $<0.001$ & & $<0.05$ & $<0.0001$ & $<0.001$ & $<0.00001$ & $<0.005$ & $<0.01$ & $<0.0005$ & $<0.00001$ \\
\hline $\begin{array}{l}\text { Central- } \\
\text { Temporal }\end{array}$ & $<0.00001$ & $<0.05$ & & $<0.00001$ & n.s & $<0.01$ & $<0.00001$ & n.s & n.s & $<0.00001$ \\
\hline $\begin{array}{l}\text { Frontal- } \\
\text { Parietal } \\
\end{array}$ & n.s. & $<0.0001$ & $<0.00001$ & & $<0.00001$ & $<0.00001$ & n.s & $<0.00001$ & $<0.00001$ & $<0.00001$ \\
\hline $\begin{array}{l}\text { Central- } \\
\text { Parietal }\end{array}$ & $<0.00001$ & $<0.001$ & n.s & $<0.00001$ & & n.s & $<0.00001$ & n.s & n.s & $<0.00001$ \\
\hline $\begin{array}{c}\text { Temporal- } \\
\text { Parietal }\end{array}$ & $<0.00001$ & $<0.00001$ & $<0.01$ & $<0.00001$ & n.s & & $<0.00001$ & n.s & n.s & $<0.00005$ \\
\hline $\begin{array}{l}\text { Frontal- } \\
\text { Occipital }\end{array}$ & n.s. & $<0.005$ & $<0.00001$ & n.s & $<0.00001$ & $<0.00001$ & & $<0.00001$ & $<0.00001$ & $<0.00001$ \\
\hline $\begin{array}{l}\text { Central- } \\
\text { Occipital }\end{array}$ & $<0.00001$ & $<0.01$ & n.s & $<0.00001$ & n.s & n.s & $<0.00001$ & & n.s & $<0.00001$ \\
\hline $\begin{array}{l}\text { Temporal- } \\
\text { Occipital }\end{array}$ & $<0.00001$ & $<0.0005$ & n.s & $<0.00001$ & n.s & n.s & $<0.00001$ & n.s & & $<0.00001$ \\
\hline $\begin{array}{l}\text { Parietal } \\
\text { Occipital }\end{array}$ & $<0.00001$ & $<0.00001$ & $<0.00001$ & $<0.00001$ & $<0.00001$ & $<0.00005$ & $<0.00001$ & $<0.00001$ & $<0.00001$ & \\
\hline
\end{tabular}


Figure 1

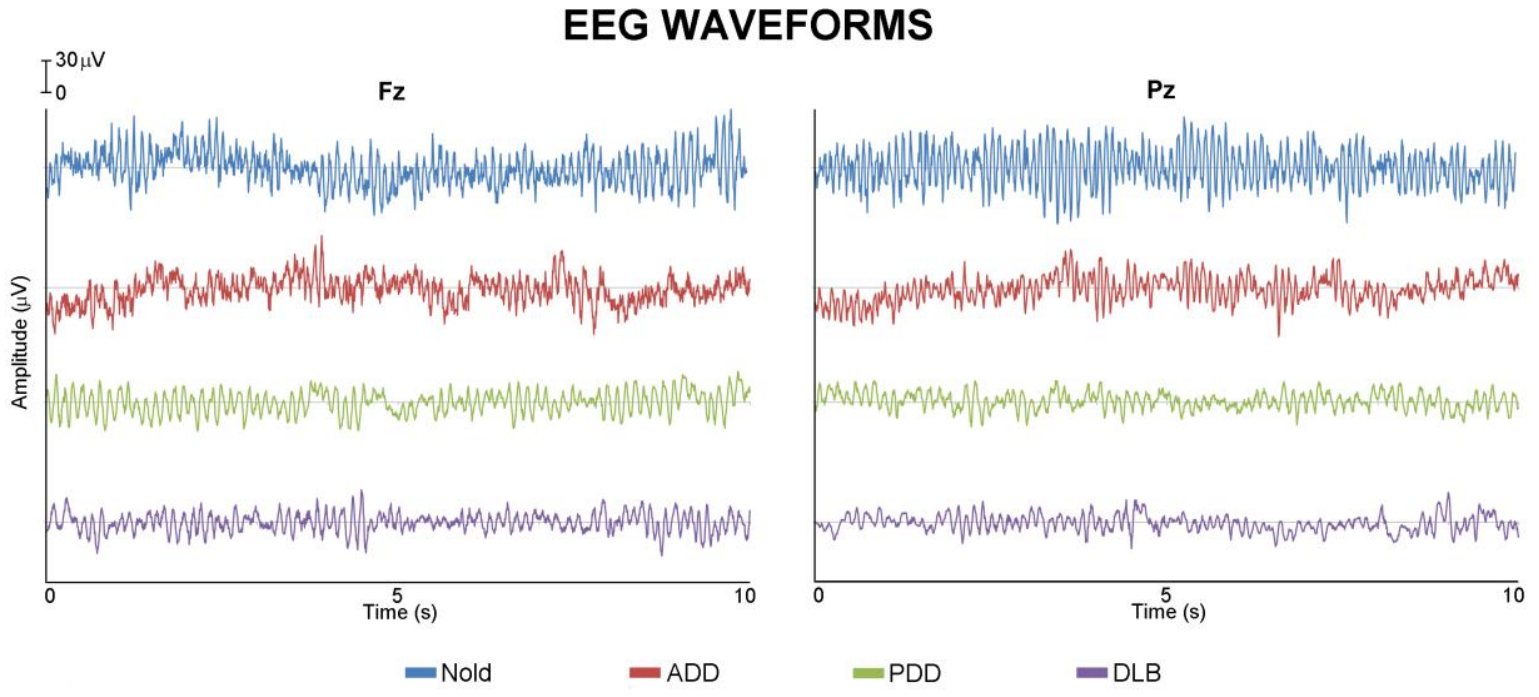


Figure 2

Interhemispheric lagged linear connectivity

STATISTICAL ANOVA INTERACTION AMONG GROUP, BAND, ROI
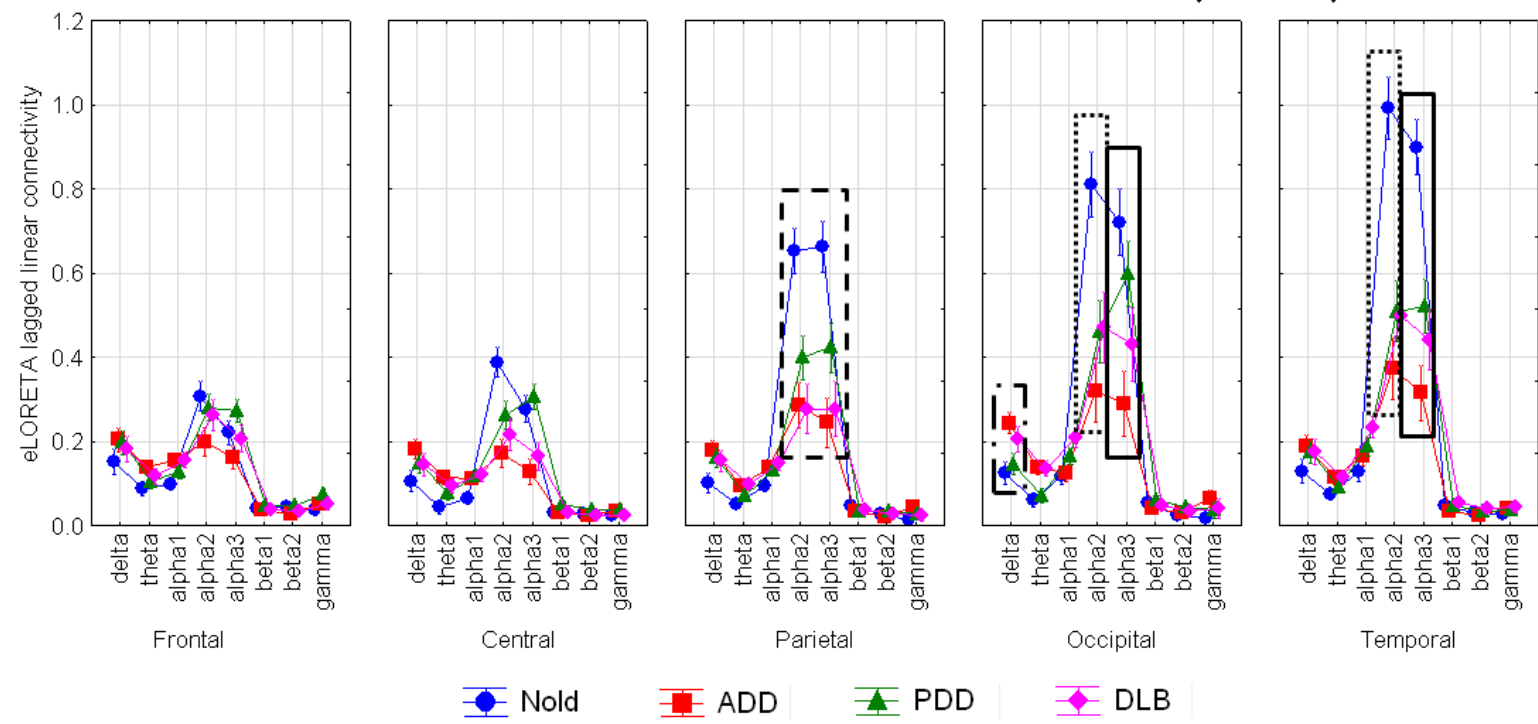

$\square$ ADD $<$ DLB $<$ PDD $<$ Nold $(p<0.05)$

:........... ADD $<$ DLB, PDD < Nold $(p<0.05)$

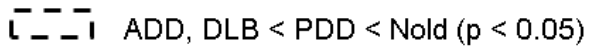

$[\cdot-$ ADD $>$ Nold, $\operatorname{PDD}(p<0.05)$ 
Figure 3

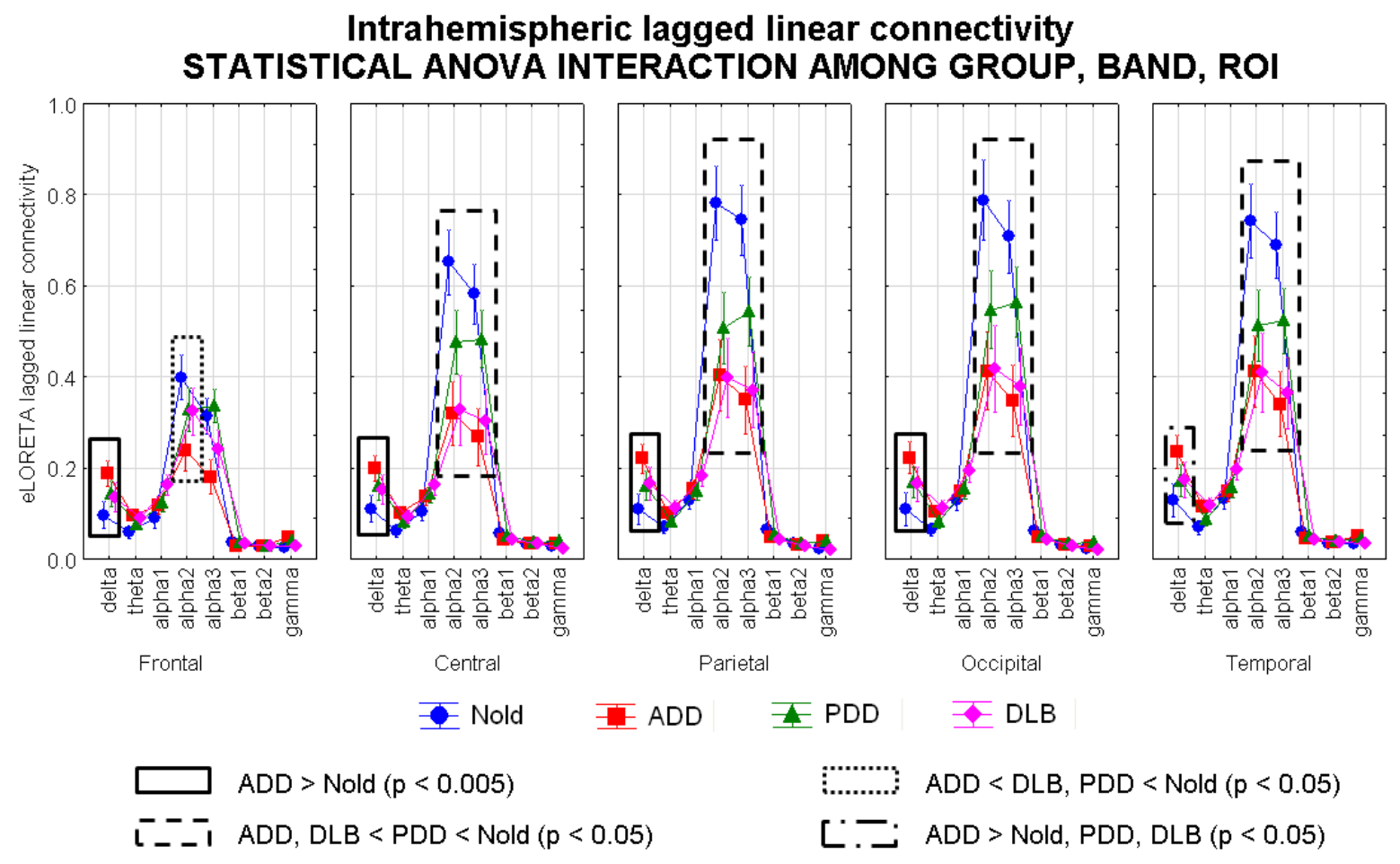


Figure 4

Individual values of interhemispheric lagged linear connectivity

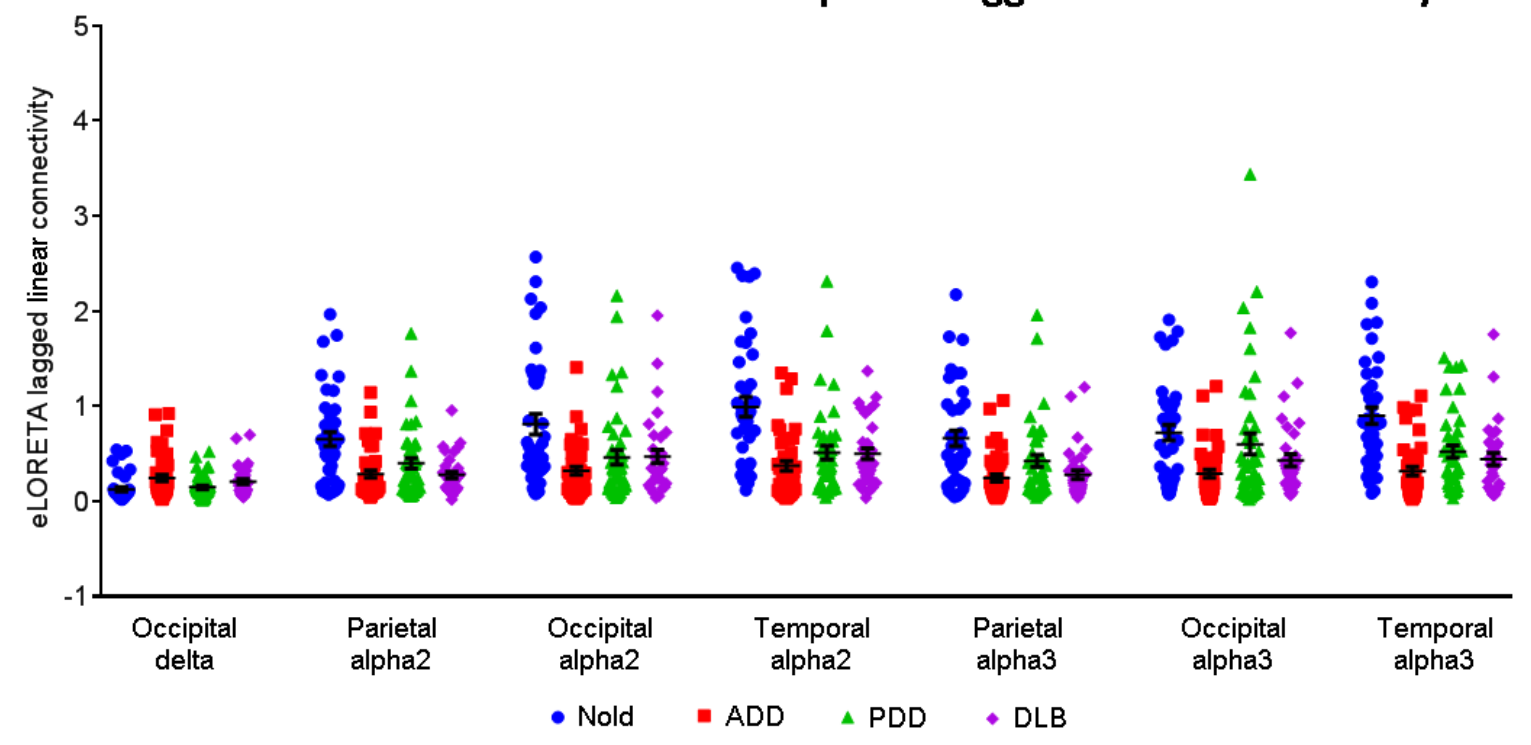


Figure 5
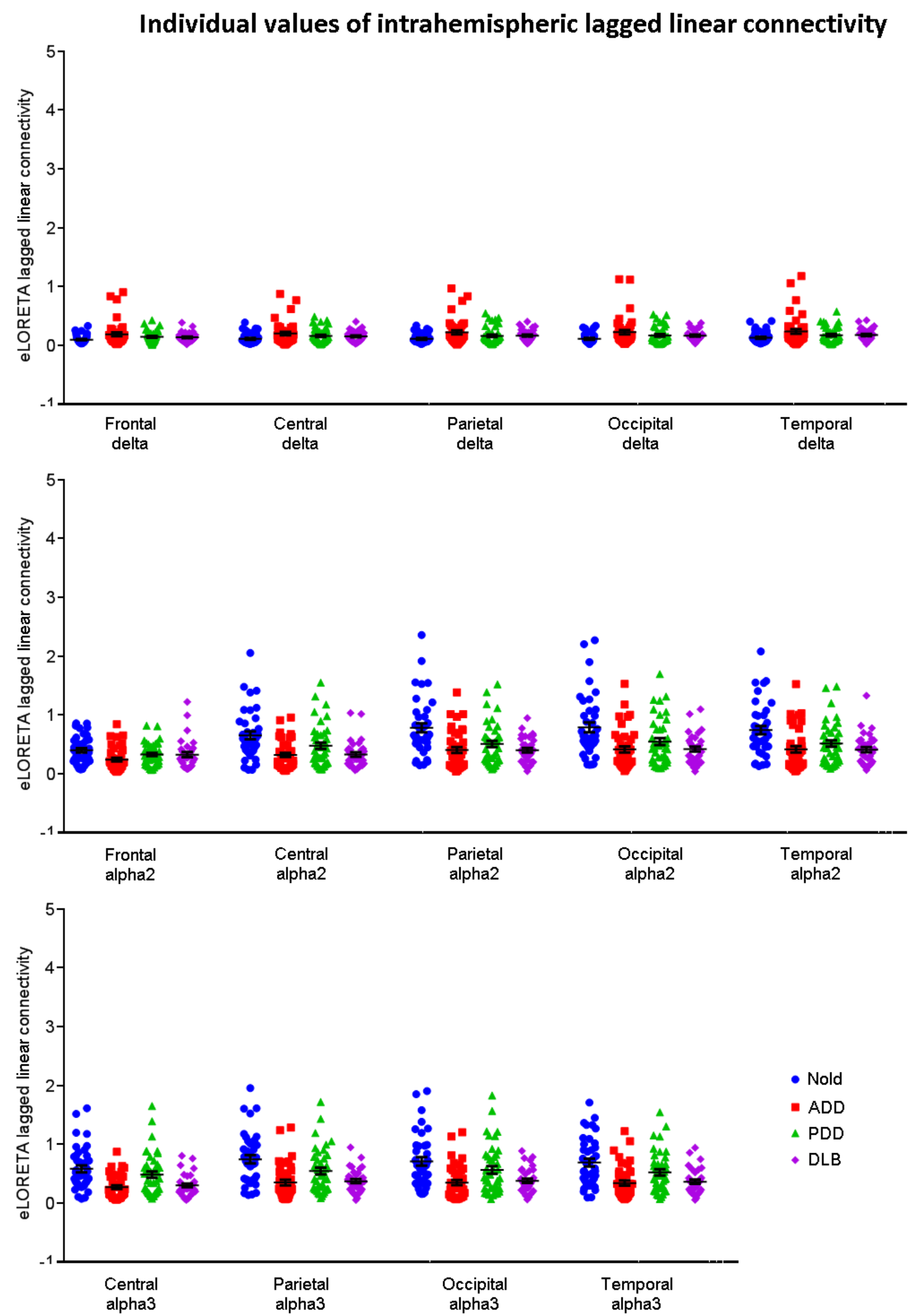
Figure 6

Scatterplot between lagged linear connectivity vs. MMSE score across Nold, ADD, PDD and DLB as a whole group
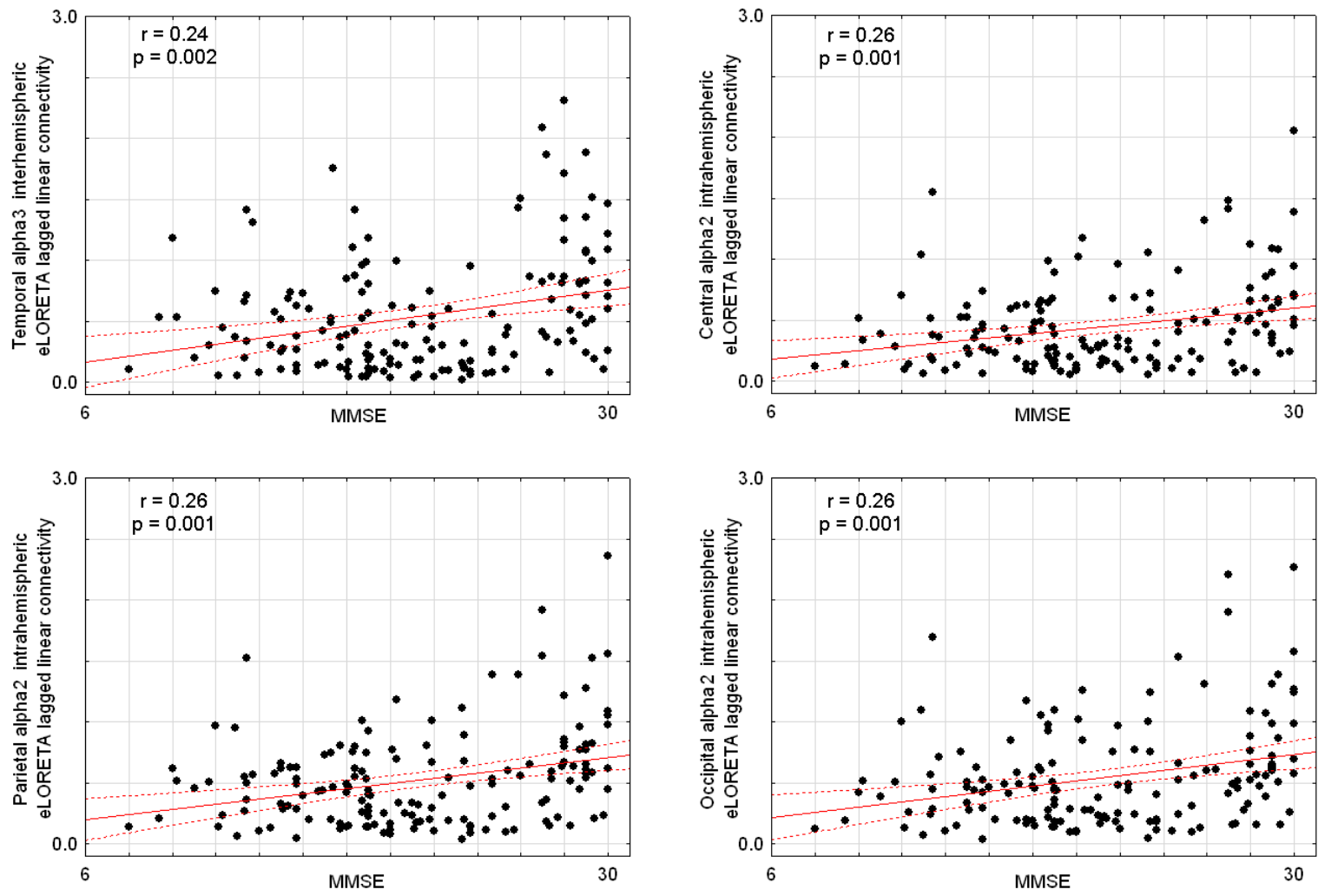
Figure 7

Classification among Nold, AD, PDD, and DLB individuals based on eLORETA lagged linear connectivity of rsEEG rhythms

Nold vs. ADD

Temporal alpha3 interhemispheric lagged linear connectivity

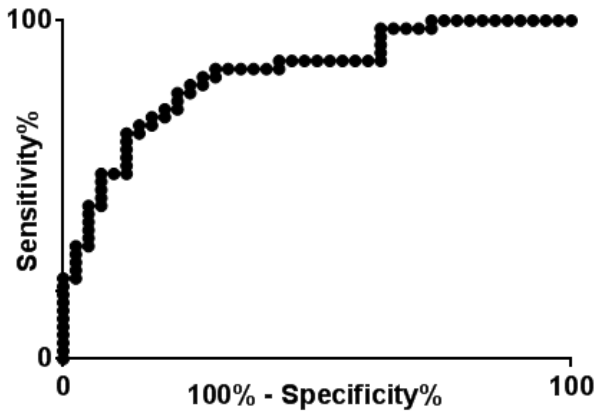

Nold vs. PDD

Temporal alpha2 interhemispheric lagged linear connectivity

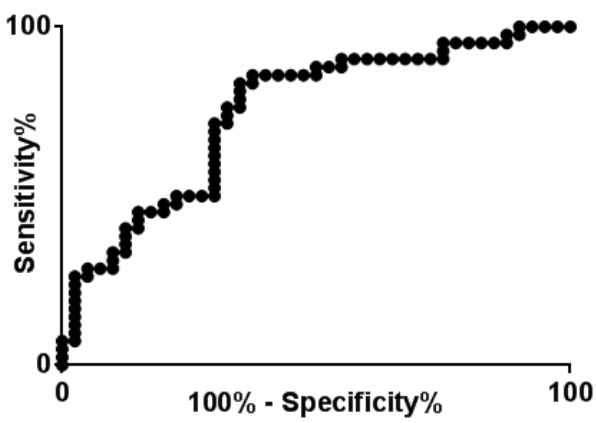

Nold vs. DLB Central alpha2 intrahemispheric lagged linear connectivity

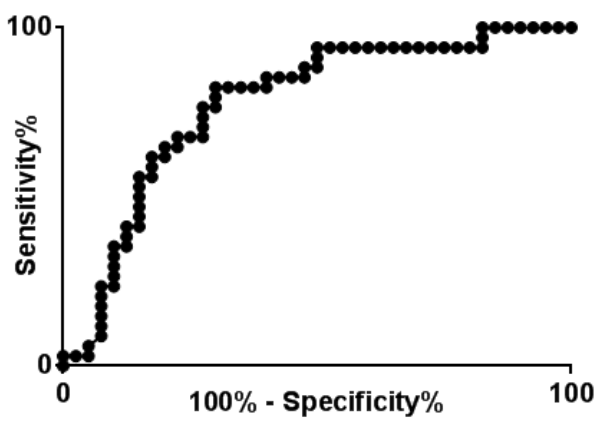


Figure 8

ALPHA INTRAHEMISPHERIC LAGGED LINEAR CONNECTIVITY
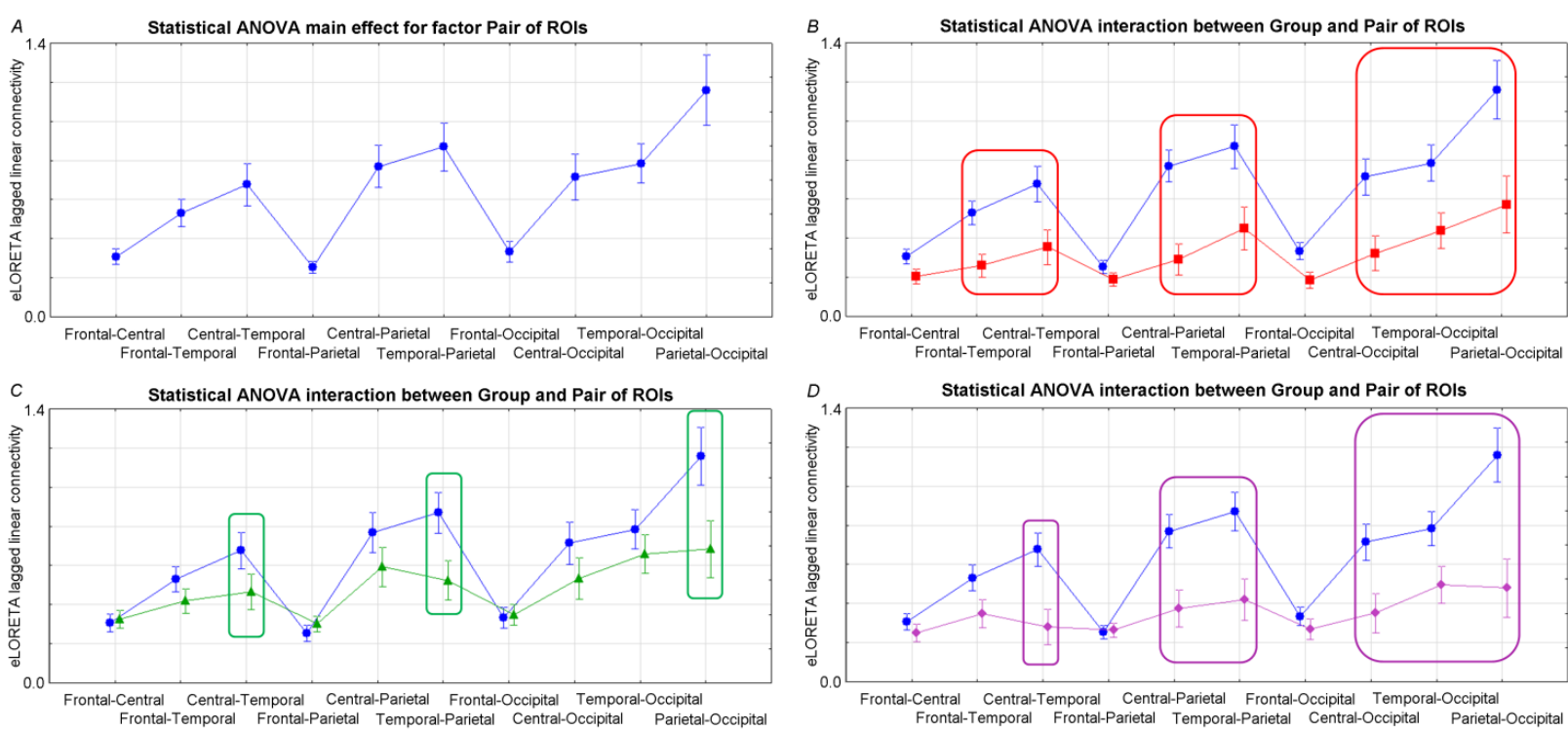

- Nold IADD \#PDD FDLB

$\square$ Nold > ADD $(p<0.05) \square$ Nold > PDD $(p<0.05) \square$ Nold > DLB $(p<0.05)$ 